\title{
Evaluation of Variable Refrigerant Flow Systems Performance on Oak Ridge National Laboratory's Flexible Research Platform: Part 1 Cooling Season Analysis
}

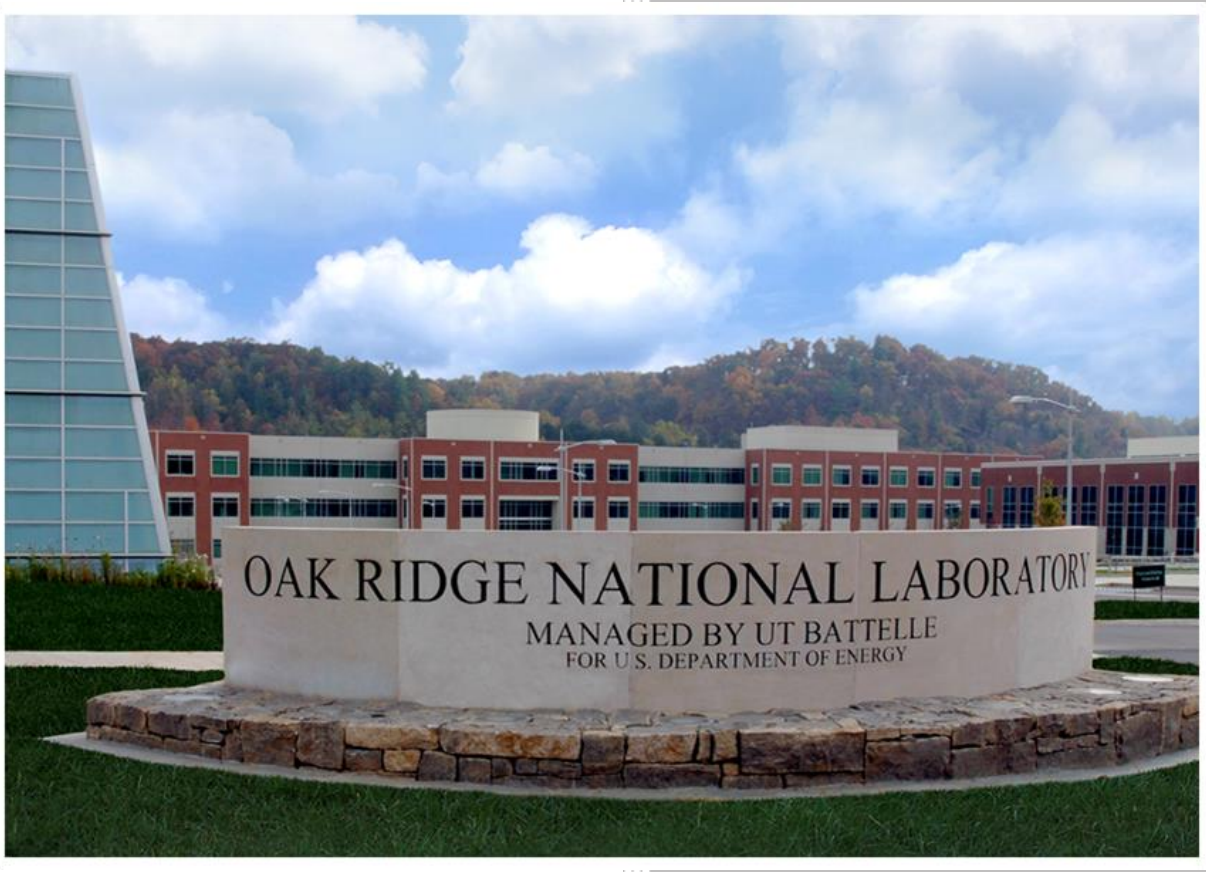

Piljae Im, PhD Mini Malhotra, PhD Jeffrey D. Munk

\section{August 2016}




\section{DOCUMENT AVAILABILITY}

Reports produced after January 1, 1996, are generally available free via US Department of Energy (DOE) SciTech Connect.

Website http://www.osti.gov/scitech/

Reports produced before January 1, 1996, may be purchased by members of the public from the following source:

National Technical Information Service

5285 Port Royal Road

Springfield, VA 22161

Telephone 703-605-6000 (1-800-553-6847)

TDD 703-487-4639

Fax 703-605-6900

E-mail info@ntis.gov

Website http://www.ntis.gov/help/ordermethods.aspx

Reports are available to DOE employees, DOE contractors, Energy Technology Data Exchange representatives, and International Nuclear Information System representatives from the following source:

Office of Scientific and Technical Information

PO Box 62

Oak Ridge, TN 37831

Telephone 865-576-8401

Fax 865-576-5728

E-mail reports@osti.gov

Website http://www.osti.gov/contact.html

This report was prepared as an account of work sponsored by an agency of the United States Government and Samsung Electronics. Neither the United States Government nor any agency thereof, nor any of their employees, makes any warranty, express or implied, or assumes any legal liability or responsibility for the accuracy, completeness, or usefulness of any information, apparatus, product, or process disclosed, or represents that its use would not infringe privately owned rights. Reference herein to any specific commercial product, process, or service by trade name, trademark, manufacturer, or otherwise, does not necessarily constitute or imply its endorsement, recommendation, or favoring by the United States Government or any agency thereof. The views and opinions of authors expressed herein do not necessarily state or reflect those of the United States Government or any agency thereof. 


\section{Energy and Transportation Science Division}

\section{Evaluation of Variable Refrigerant Flow Systems Performance on Oak Ridge National Laboratory's Flexible Research Platform: Part 1 Cooling Season Analysis}

Piljae Im, PhD

Mini Malhotra, $\mathrm{PhD}$

Jeffrey D. Munk

Date Published: August 2016

Prepared by

OAK RIDGE NATIONAL LABORATORY

Oak Ridge, TN 37831-6283

managed by

UT-BATTELLE, LLC

for the

US DEPARTMENT OF ENERGY

under contract DE-AC05-00OR22725 



\section{CONTENTS}

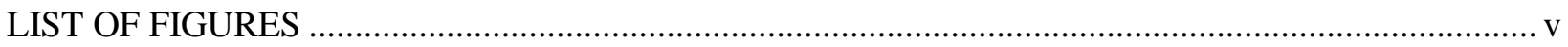

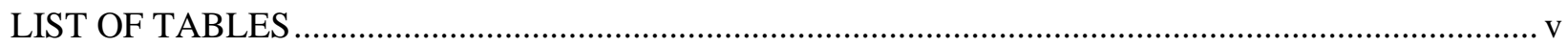

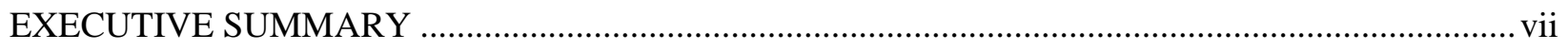

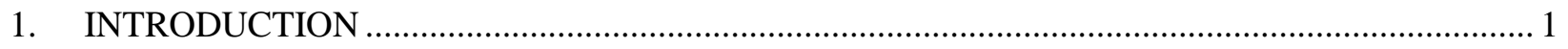

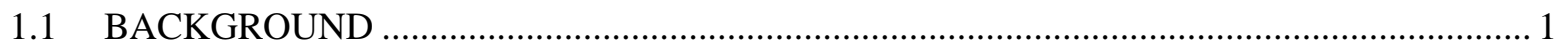

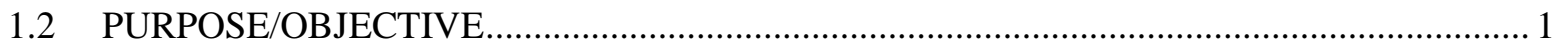

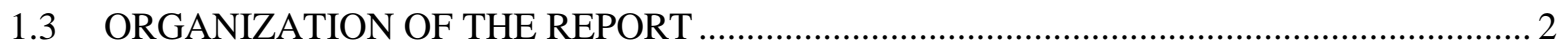

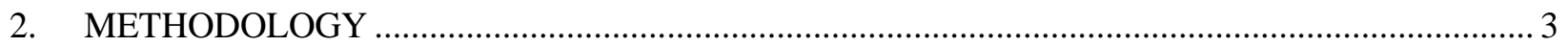

2.1 TEST FACILITY: TWO-STORY FLEXIBLE RESEARCH PLATFORM ......................... 3

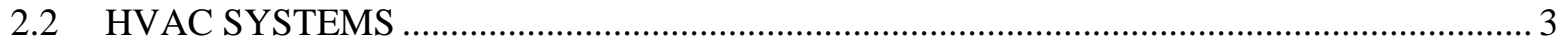

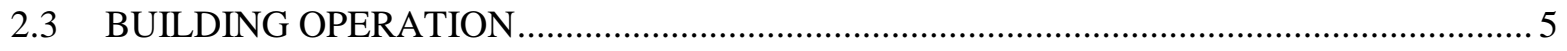

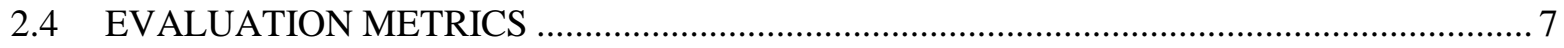

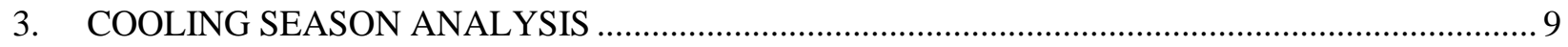

3.1 HOURLY THERMAL CONDITION ANALYSIS - OCCUPIED HOURS ONLY ................ 9

3.2 PERFORMANCE DURING TYPICAL SUMMER DAYS ............................................ 10

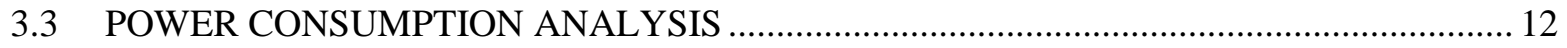

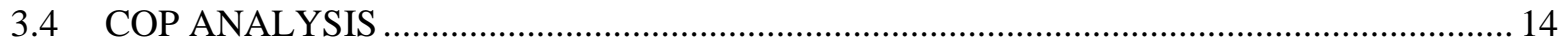

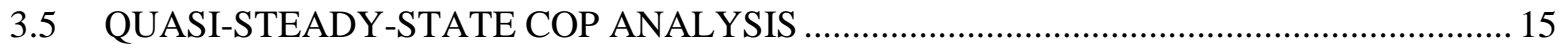

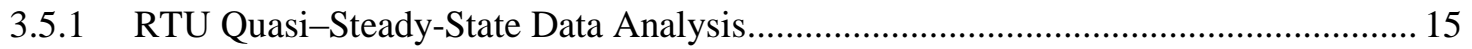

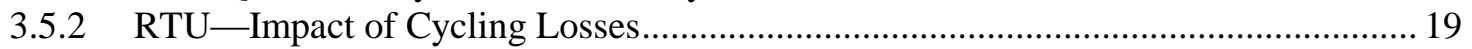

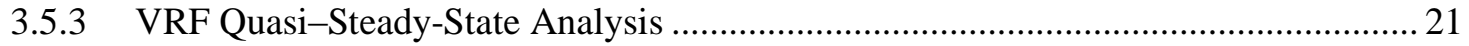

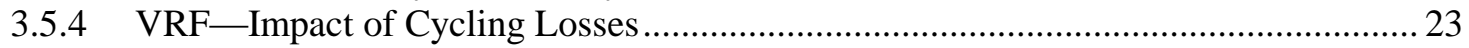

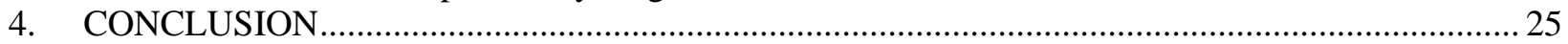

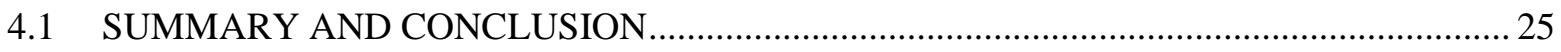

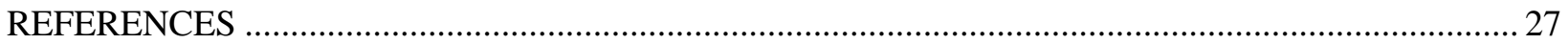

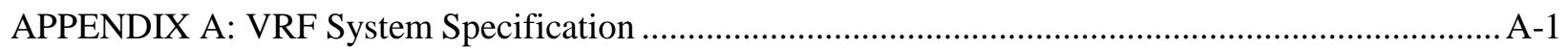





\section{LIST OF FIGURES}

Figure 1. Test facility (left), VRF system outdoor unit (center) and indoor unit (right).......................... 3

Figure 2. System schematic and monitoring points for RTU system (above) and VRF system

(below).

Figure 3. Outdoor air reset schedule for RTU discharge temperature. .............................................. 5

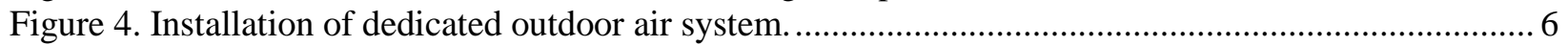

Figure 5. Schematic of operation to emulate (a) 50\% load, (b) 75\% load, and (c) 100\% load................... 6

Figure 6. Room temperatures during RTU and VRF system operation at different capacities. ................. 10

Figure 7. Room temperature and energy use for a typical day during RTU and VRF system

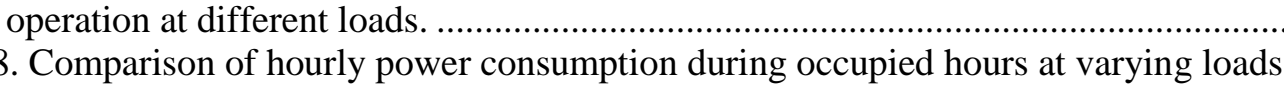

Figure 8. Comparison of hourly power consumption during occupied hours at varying loads.
(Left) Data points from the VRF system operation; (right) data points from RTU system.......... 12

Figure 9. Comparison of power consumption by VRF and RTU systems at each load condition......

Figure 10. Energy savings from VRF system at different loads.

Figure 11. COP comparison between RTU and VRF systems (top: 100\% operation; center: $75 \%$

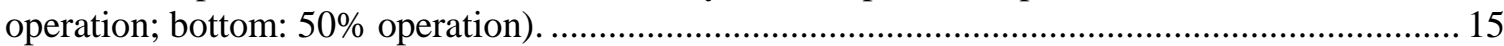

Figure 12. Determination of quasi-steady-state minimum time into cycle for RTU.............................. 16

Figure 13. Comparison of RTU efficiency during different schedules and under different outdoor

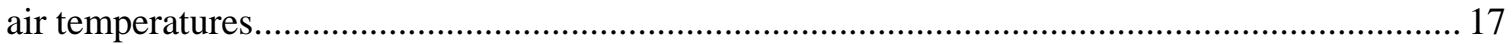

Figure 14. Comparison of RTU indoor airflow during different schedules......................................... 18

Figure 15. Comparison of RTU ratio of supply airflow to total cooling during different schedules.......... 18

Figure 16. Comparison of RTU sensible heat ratio during different schedules...................................... 19

Figure 17. Comparison of RTU average compressor runtime per cycle for different operation

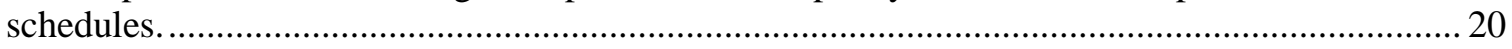

Figure 18. Comparison of cycling losses for the RTU during different operation schedules.................... 20

Figure 19. Comparison of VRF efficiency during different operating schedules.................................. 22

Figure 20. Impact of the rated capacity of active indoor units on the efficiency of the VRF system.

Figure 21. Efficiency of VRF system when the rated cooling capacity of the active indoor units divided by the total rated cooling capacity was at least 0.80 ......

Figure 22. Comparison of efficiency for VRF system operating during different schedules for all data and quasi-steady-state data only.

\section{LIST OF TABLES}

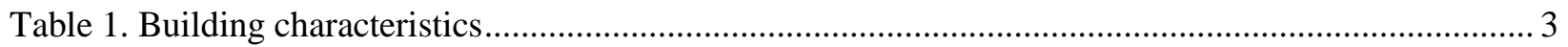

Table 2. Summer season operation schedule ….......................................................................... 7

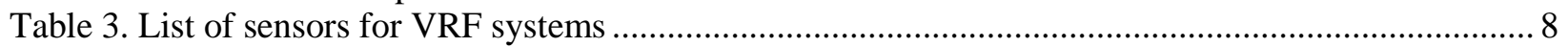

Table 4. Regression models for power consumption for cooling season............................................... 14 



\section{EXECUTIVE SUMMARY}

This report provides second-year cooling season test results for the multi-year project titled "Evaluation of Variable Refrigeration Flow (VRF) System on Oak Ridge National Laboratory (ORNL)'s Flexible Research Platform (FRP)." The purpose of the second-year project was to (1) evaluate the full- and partload performance of VRF systems compared with an existing baseline heating, ventilation, and airconditioning (HVAC) system, which is a conventional rooftop unit (RTU) variable-air-volume (VAV) system with electric resistance heating and (2) use hourly building energy simulation to evaluate the energy savings potential of using VRF systems in major US cities. The second-year project performance period was from July 2015 through June 2016.

The performance of two HVAC systems was evaluated using ORNL's FRP, which is a two-story, $3,200 \mathrm{ft}^{2}\left(297.3 \mathrm{~m}^{2}\right)$ multi-zone unoccupied building that represents a typical small, low-rise office building type common in the US existing building stock. The FRP is equipped with a conventional 12.5 ton $(44 \mathrm{~kW})$ RTU-VAV reheat system as a baseline system. For this study, a 12 ton $(42 \mathrm{~kW})$ VRF with a dedicated outdoor air system was installed for comparison with the baseline RTU system.

During the test period, full- and part-load conditions (i.e., 100, 75, and 50\% loads) in the building were maintained alternately by conditioning either the entire building or selected zones and emulating the occupancy accordingly. During the study period, each system was operated alternately under each of the three load conditions for 2-3 days; and the system parameters, indoor and outdoor conditions, loads, and energy use were monitored. The cooling and heating season performance and energy use of both systems was monitored from the summer of 2015 through the winter of 2016 . The system performance was evaluated in terms of weather-normalized HVAC energy consumption, the ability to maintain the desired indoor temperature in the conditioned zones, and the seasonal average coefficient of performance (COP). Furthermore, the energy savings potential of using VRF systems in major US cities was evaluated using hourly building energy simulation, which was calibrated with the measured data from the building. Three separate reports for cooling season analysis, heating season analysis, and simulation analysis are provided based on the analysis results. This report presents the cooling season analysis results.

\section{Cooling Season Analysis}

The cooling season analysis is based on the measured data from July 11, 2015, through September 12, 2015. During this period, the analysis shows that the VRF system used less energy than the baseline RTU system. The energy savings for the VRF system compared with the RTU system for the cooling season are estimated to be 30,37, and 47\% under 100, 75, and 50\% load conditions, respectively. Both the RTU and the VRF systems maintained room temperatures very well during the cooling season, although the second-floor rooms were generally slightly overheated. The data also show that the VRF system maintained room temperatures in a slightly tighter range compared with the RTU system.

The performance analysis based on 1 hour data shows that the average cooling COPs were 4.2, 3.9, and 3.7 for the VRF system and 3.1, 3.0, and 2.5 for the RTU system under 100, 75, and 50\% load conditions, respectively. Those values show 35,30 , and $48 \%$ improvements in COP for 100,75 , and $50 \%$ load conditions, respectively.

Further analysis of system performance was performed using 1-minute-resolution data. The quasi-steadystate data analysis indicated that the VRF system operated most efficiently when all indoor units were actively cooling and the compressor was operating at reduced speed. 



\section{INTRODUCTION}

\subsection{BACKGROUND}

This report provides test results from the second year of the multi-year project titled "Evaluation of Variable Refrigeration Flow system on Oak Ridge National Laboratory's Flexible Research Platform." The research for the first year of the 3 year project was performed from July 2014 through April 2015. The purpose of the first year was to design and install a variable refrigerant flow (VRF) system in the new flexible research platform (FRP) test facility at Oak Ridge National Laboratory (ORNL), and to evaluate the energy savings potential by comparing the energy use of the VRF system with the existing baseline heating, ventilation, and air conditioning (HVAC) system, a conventional rooftop unit (RTU) with a variable-air-volume (VAV) system and electric resistance heating. In addition, a newly developed enhanced control algorithm called CCM (the comfort control method), was implemented to estimate additional energy savings potential. The final report from the first year includes the background of the research, FRP building characteristics, baseline HVAC and VRF system characteristics, and the final results of the estimated energy savings of the VRF system and CCM control algorithm (Im et al. 2015).

Based on the lessons and findings from the project's first year and further discussions with the manufacturer, the goal of the second year was developed. The first-year research confirmed the potential of a VRF system to reduce energy use and enhance indoor thermal comfort. At the same time, it emphasized the need to explore several other aspects of the performance of the VRF systems, including the following.

- Analysis of part-load performance of VRF and baseline HVAC system: VRF systems are noted for their superior part-load performance compared with conventional HVAC systems. Future study could include evaluation and comparison of the part-load performance of the VRF system and baseline system in ORNL's FRP.

- Analysis of VRF and baseline HVAC system performance in different climates: To evaluate the performance of a VRF system in different climates, a simulation-based energy analysis could be performed. A building energy model could be developed, calibrated using the measured VRF and the baseline HVAC system performance data, and simulated with corresponding typical meteorological year weather files.

- Application of a dedicated outdoor air system (DOAS): After the first year, it was suggested that a DOAS be included with the VRF system to provide adequate fresh air to the indoor space according to the requirements of the American Society of Heating, Refrigeration and Air-Conditioning Engineers (ASHRAE) Standard 62.1 (ASHARE 2013). During the first year, unconditioned outdoor air was introduced into the plenum space by continuous operation of an exhaust fan.

\subsection{PURPOSE/OBJECTIVE}

Therefore, for the second year project, the following two main research objectives are defined.

1. To modify the previously installed VRF system and add the DOAS on the two-story FRP as one of multiple HVAC options and compare the full- and part-load performance with that of another baseline HVAC system (i.e., a rooftop packaged HVAC with VAV reheat).

2. To evaluate the energy savings potential of using VRF systems in various US climate zones based on calibrated simulation modeling. 


\subsection{ORGANIZATION OF THE REPORT}

Chapter 2 describes a methodology to evaluate the full- and part-load performance of VRF systems compared with that of the baseline RTU system and to use calibrated simulation modeling to evaluate nationwide the energy savings potential of VRF systems. Chapter 3 presents the cooling season data analysis to evaluate the energy use and indoor conditions for different HVAC operation scenarios. Indepth performance analyses for each system for the cooling season are also discussed. Finally, Chapter 4 concludes the study with a summary, findings, lessons learned, and a discussion of future work. 


\section{METHODOLOGY}

\subsection{TEST FACILITY: TWO-STORY FLEXIBLE RESEARCH PLATFORM}

The test facility is a two-story, 3,200 $\mathrm{ft}^{2}\left(297.3 \mathrm{~m}^{2}\right)$ multi-zone unoccupied building that represents a typical low-rise, small office building common in the US existing building stock (Figure 1, left). The occupancy in the building can be simulated by process control of lighting and other internal loads. On this building, retrofits and alternative building components and systems can be implemented and their performance monitored. In addition, a dedicated weather station is installed on the roof that provides actual weather data for use in performance analysis and energy modeling. The building is equipped with a conventional 12.5 ton $(44 \mathrm{~kW})$ RTU-VAV reheat system. For this study, a 12 ton ( $42 \mathrm{~kW}) \mathrm{VRF}$ with a DOAS was installed (Figure 1, center and right), and the existing RTU system served as the baseline system. Table 1 summarizes the baseline building and system characteristics.
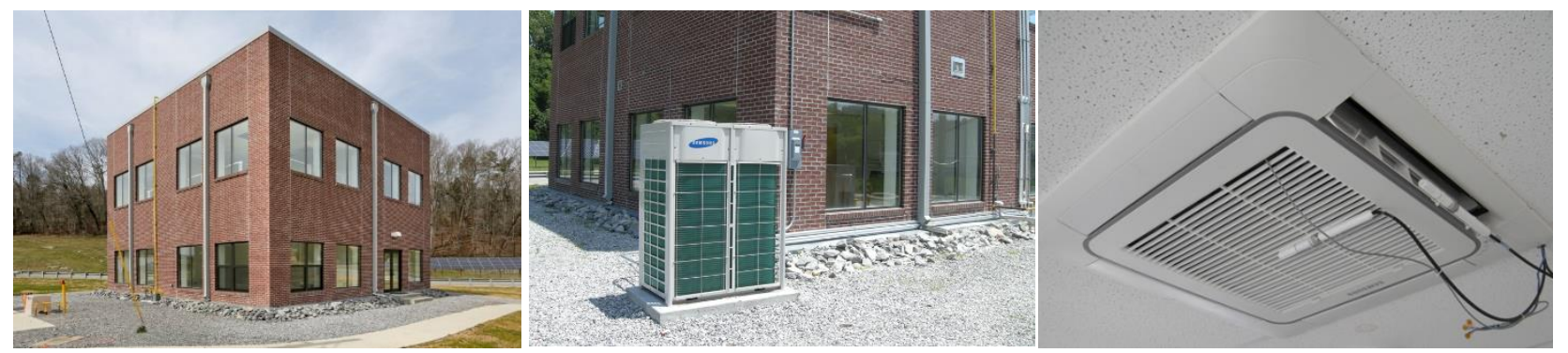

Figure 1. Test facility (left), VRF system outdoor unit (center) and indoor unit (right).

Table 1. Building characteristics

\begin{tabular}{l|l}
\hline Location & Oak Ridge, Tennessee, USA \\
Building size & Two-story, $40 \times 40 \mathrm{ft}(12.2 \mathrm{~m} \times 12.2 \mathrm{~m}), 14 \mathrm{ft}(4.3 \mathrm{~m})$ floor-to-floor height \\
Exterior walls & Concrete masonry units with face brick, $\mathrm{R}_{\mathrm{US}}-11\left(\mathrm{R}_{\mathrm{SI}}-1.9\right)$ fiberglass insulation \\
Floor & Slab-on-grade \\
Roof & Metal deck with $\mathrm{R}_{\mathrm{US}}-18\left(\mathrm{R}_{\mathrm{SI}}-3.17\right)$ polyisocyanurate insulation \\
Windows & Double-pane clear glazing, $28 \%$ window-to-wall ratio \\
Baseloads & $0.85 \mathrm{~W} / \mathrm{ft}^{2}\left(9.18 \mathrm{~W} / \mathrm{m}^{2}\right)$ lighting power density, $1.3 \mathrm{~W} / \mathrm{ft}^{2}\left(14.04 \mathrm{~W} / \mathrm{m}^{2}\right)$ equipment \\
Baseline HVAC system & $\begin{array}{l}12.5 \text { ton, } 9.7 \mathrm{EER} \text { rooftop unit; } 81 \% \text { AFUE natural gas furnace; VAV terminal units } \\
\text { and electric reheat }\end{array}$ \\
VRF system & 12 ton $(42 \mathrm{~kW})$ VRF system with a DOAS \\
\hline
\end{tabular}

\subsection{HVAC SYSTEMS}

Figure 2 shows a schematic of the two systems. The RTU provides direct expansion cooling, heating with a natural gas furnace, and electric resistance reheat at VAV terminal units. The return air is drawn from each room through an above-ceiling plenum on each floor. Fresh air is introduced through the fan of the DOAS to provide adequate ventilation in accordance with ASHRAE Standard 62.1-2013 (ASHRAE 2013). An exhaust fan is located on each floor and operates continuously. The RTU is programmed to maintain a constant discharge air temperature at $14^{\circ} \mathrm{C}\left(57^{\circ} \mathrm{F}\right)$ during the cooling season. 

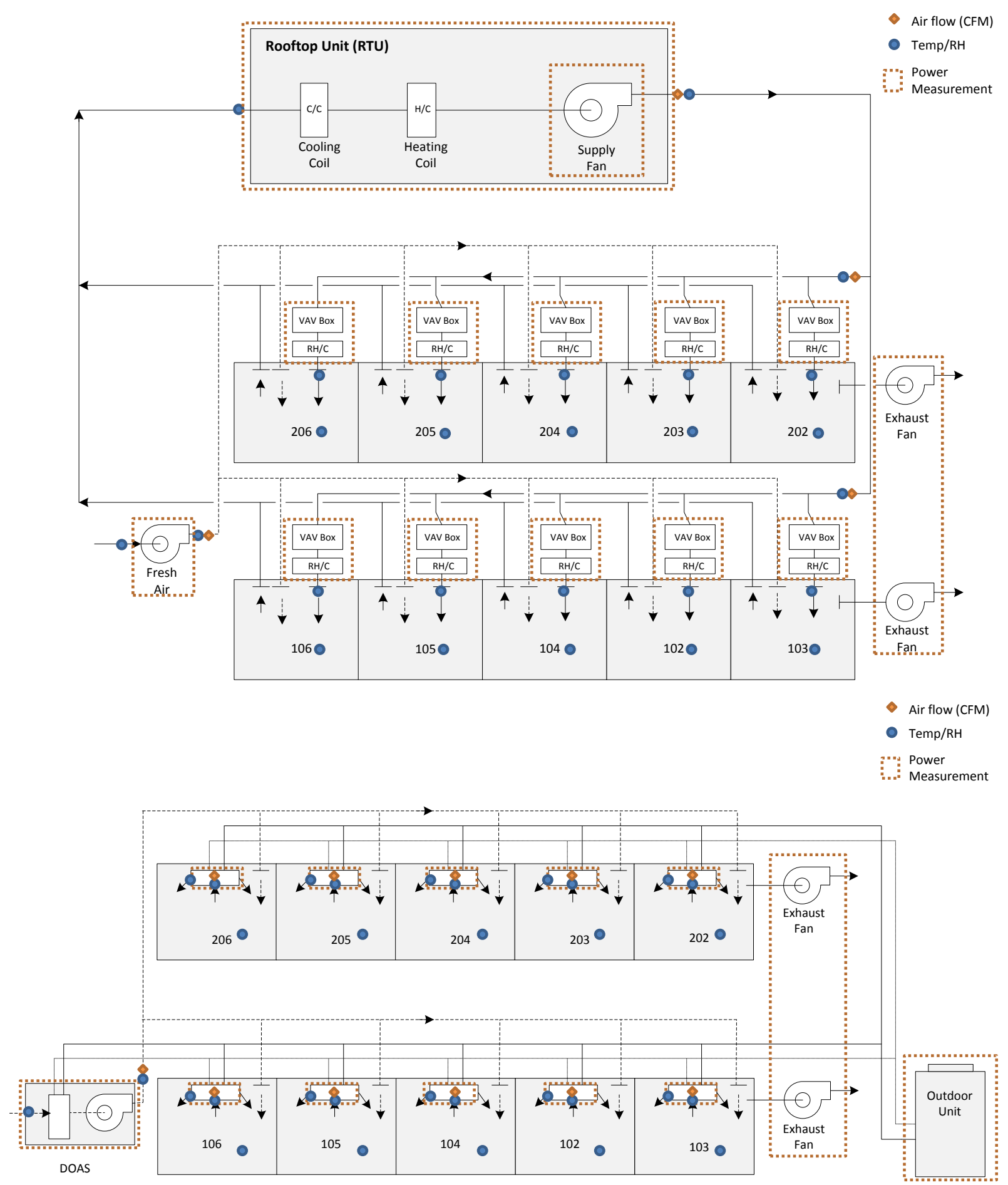

Figure 2. System schematic and monitoring points for RTU system (above) and VRF system (below). 
During the heating season, the RTU discharge air temperature was adjusted based on an outdoor air reset schedule (See Figure 3). The natural gas furnace would engage if the return air temperature to the RTU dropped below the discharge air set point temperature. In cooling mode (i.e., discharge temperature set at $14^{\circ} \mathrm{C}$ ), the electric resistance reheat in the VAV terminal boxes in individual zones would activate to provide the necessary heat to maintain the desired zone temperature.

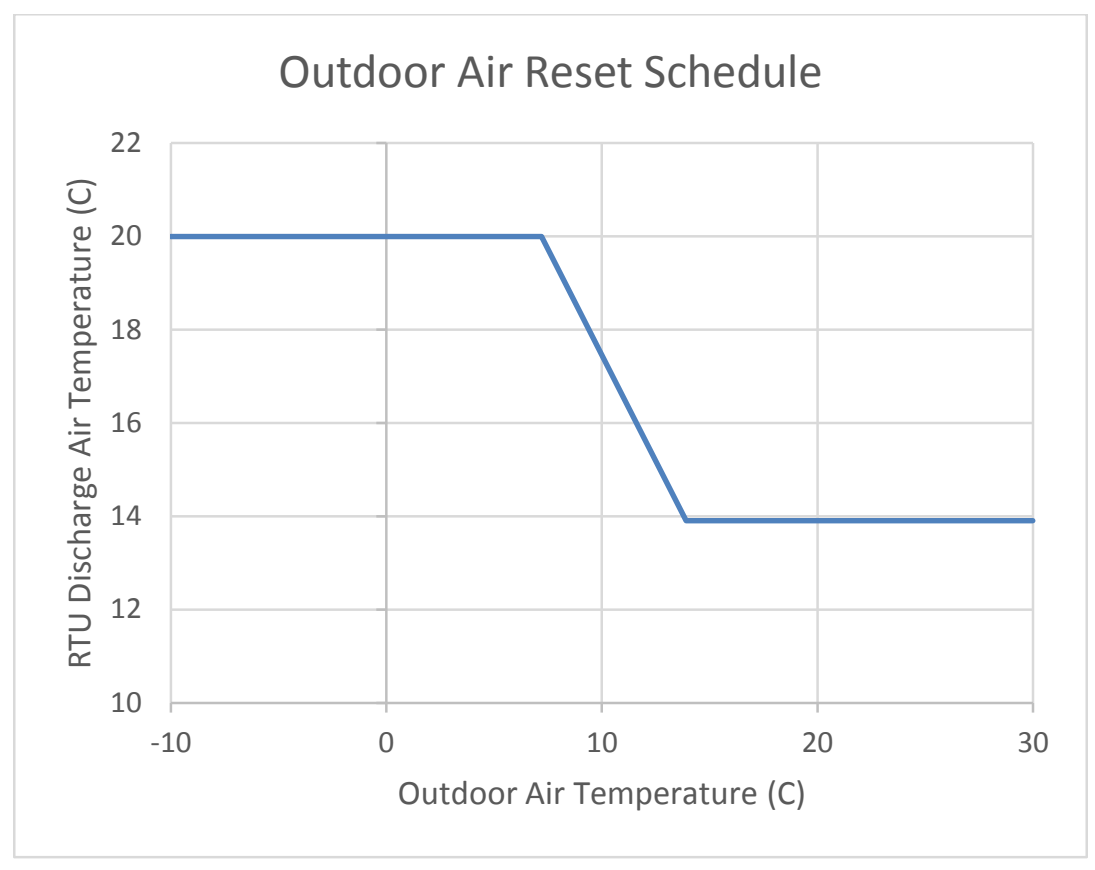

Figure 3. Outdoor air reset schedule for RTU discharge temperature.

The VRF system has a 12 ton (42 kW) outdoor unit, one DOAS unit, and ten indoor units with capacities ranging from 0.5 to 1.5 tons $(1.8-5.3 \mathrm{~kW})$. Appendix A provides full specifications for the outdoor and indoor units. The ten indoor units and the DOAS (Figure 4) are connected to the same VRF outdoor condensing unit, and the DOAS provides conditioned outdoor air to ten zones. Note that the VRF system in this test is a heat pump-type system that provides only cooling or heating at any single time and cannot provide simultaneous heating and cooling for different thermal zones.

\subsection{BUILDING OPERATION}

The performance of the VRF and the baseline RTU systems was evaluated by comparing their hourly and daily energy use and the indoor thermal condition (i.e., temperature). In year 1, the entire building was conditioned for the performance evaluation, which has a limitation in part-load performance evaluation. In year 2, the building was partially and fully conditioned to compare the part-load performance of the systems in more detail. Figure 5 illustrates the schematic of operation to emulate (a) $50 \%$ load, (b) $75 \%$ load, and (c) $100 \%$ load. ${ }^{1}$ Each system was operated alternately for 8 consecutive days with 3 days each at $50 \%$ and $75 \%$ and 2 days at $100 \%$ loads. Unlike in year 1, there was no discrete weekday and weekend schedule, and the same occupancy schedule was used for all days. Table 2 provides each schedule for the cooling season.

\footnotetext{
${ }^{1}$ The operation scenarios were named $50 \%$ and $75 \%$ loads based on the combined rated capacity of the indoor units.
} 


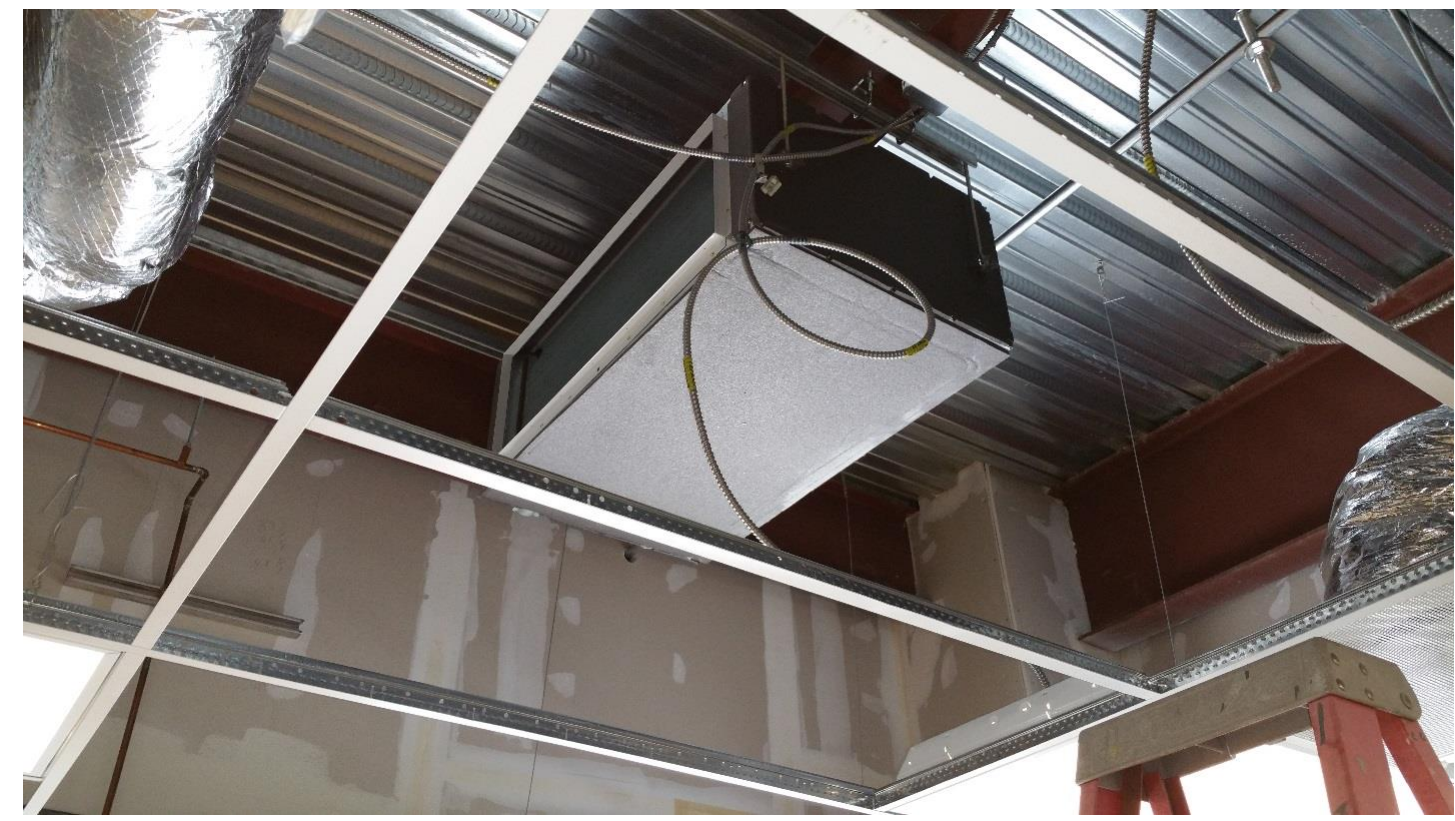

Figure 4. Installation of dedicated outdoor air system.

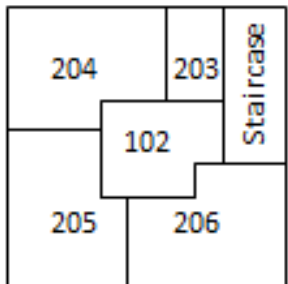

Secondfloor

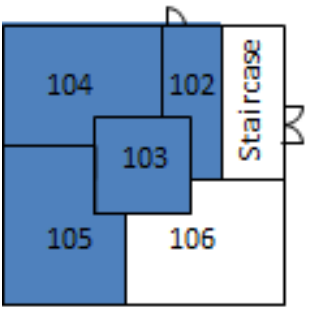

First floor

$50 \%$ load

(a)

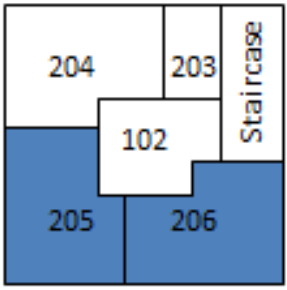

Secondfloor

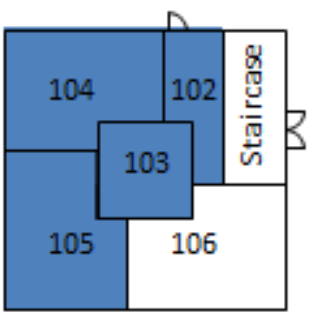

First floor

$75 \%$ load

(b)

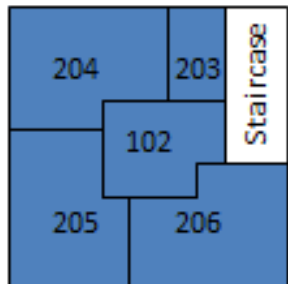

Secondfloor

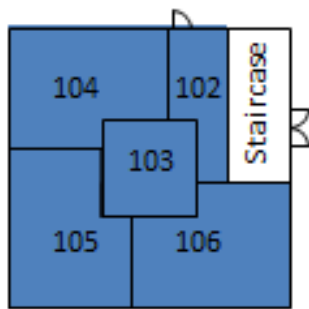

First floor

$100 \%$ load

(c)

Figure 5. Schematic of operation to emulate (a) $50 \%$ load, (b) $75 \%$ load, and (c) $100 \%$ load.

As shown in Table 2, the cooling season analysis is based on the measured data from July 11, 2015, through September 12, 2015. During this period, the RTU system was operated for 9 days at 50\% load, 13 days at $75 \%$ load, and 8 days at $100 \%$ load. The VRF system was operated for 9 days at $50 \%$ load, 9 days at $75 \%$ load, and 6 days at $100 \%$ load.

Based on the schedule, occupancy emulation was also controlled so that only conditioned rooms had emulated occupancy. 
Table 2. Summer season operation schedule

\begin{tabular}{|c|c|c|c|c|c|c|c|c|c|c|c|c|c|}
\hline Date & RTU50 & RTU75 & RTU100 & VRF50 & VRF75 & VFR100 & Date & RTU50 & RTU75 & RTU100 & VRF50 & VRF75 & VFR100 \\
\hline 11-Jul & & & & & & & 12-Aug & & & & & & \\
\hline 12-Jul & & & & & & & 13-Aug & & & & & & \\
\hline 13-Jul & & & & & & & 14-Aug & & & & & & \\
\hline 14-Jul & & & & & & & 15-Aug & & & & & & \\
\hline 15-Jul & & & & & & & 16-Aug & & & & & & \\
\hline 16-Jul & & & & & & & 17-Aug & & & & & & \\
\hline 17-Jul & & & & & & & $18-\mathrm{Aug}$ & & & & & & \\
\hline 18-Jul & & & & & & & 19-Aug & & & & & & \\
\hline 19-Jul & & & & & & & 20-Aug & & & & & & \\
\hline 20-Jul & & & & & & & 21-Aug & & & & & & \\
\hline 21-Jul & & & & & & & 22-Aug & & & & & & \\
\hline 22-Jul & & & & & & & 23-Aug & & & & & & \\
\hline 23-Jul & & & & & & & 24-Aug & & & & & & \\
\hline 24-Jul & & & & & & & 25-Aug & & & & & & \\
\hline 25-Jul & & & & & & & 26-Aug & & & & & & \\
\hline 26-Jul & & & & & & & 27-Aug & & & & & & \\
\hline 27-Jul & & & & & & & 28-Aug & & & & & & \\
\hline 28-Jul & & & & & & & 29-Aug & & & & & & \\
\hline 29-Jul & & & & & & & 30-Aug & & & & & & \\
\hline 30-Jul & & & & & & & 31-Aug & & & & & & \\
\hline 31-Jul & & & & & & & 1-Sep & & & & & & \\
\hline 1-Aug & & & & & & & 2-Sep & & & & & & \\
\hline 2-Aug & & & & & & & 3-Sep & & & & & & \\
\hline 3-Aug & & & & & & & 4-Sep & & & & & & \\
\hline 4-Aug & & & & & & & 5-Sep & & & & & & \\
\hline 5-Aug & & & & & & & 6-Sep & & & & & & \\
\hline 6-Aug & & & & & & & 7-Sep & & & & & & \\
\hline 7-Aug & & & & & & & 8-Sep & & & & & & \\
\hline 8-Aug & & & & & & & 9-Sep & & & & & & \\
\hline 9-Aug & & & & & & & 10-Sep & & & & & & \\
\hline 10-Aug & & & & & & & 11-Sep & & & & & & \\
\hline 11-Aug & & & & & & & 12-Sep & & & & & & \\
\hline
\end{tabular}

\subsection{EVALUATION METRICS}

The performance of the RTU and VRF systems was compared in terms of (1) energy use, (2) ability to maintain room temperature, and (3) system efficiency. The energy use and thermal performance were compared using measured hourly data for occupied hours only, excluding the startup hours (i.e., 8 a.m. to 6 p.m.). The COP analysis was performed using both hourly and 1-minute data. Figure 2 shows the airside monitoring points, which include the room temperature and relative humidity and the supply, return, and mixed-air temperatures and relative humidity. The airflow rate was measured at the RTU supply, upstairs and downstairs of the supply duct, and at the fresh air supply for the RTU system. For the VRF system, one-time air flow measurements for each indoor unit were conducted, and the DOAS supply side for the VRF system was measured continuously. Power measurements were obtained separately for the RTU unit, supply fan, and DOAS fan for the baseline RTU system. Power consumption for the VRF outdoor unit, each VRF indoor unit, and the DOAS were measured as well. Table 3 shows the list of sensors installed for the VRF system. The measured supply, return temperature and relative humidity, and airflow were used to calculate the delivered heating and cooling loads to the building and system COP, as well. 
Table 3. List of sensors for VRF systems

\begin{tabular}{|c|c|c|c|c|c|}
\hline Function & Sensor & Sensor model & Location & Quantity & Accuracy \\
\hline $\begin{array}{l}\text { Indoor } \\
\text { thermal } \\
\text { condition }\end{array}$ & Temp/RH & Campbell Sci HC2S3-L & All air side & 20 & $\begin{array}{c} \pm 0.1^{\circ} \mathrm{C} \text { and } \pm 0.1 \% \mathrm{RH} \\
@ 23^{\circ} \mathrm{C}\end{array}$ \\
\hline $\begin{array}{l}\text { condition } \\
\text { Heating } \\
\text { and } \\
\text { cooling } \\
\text { capacities }\end{array}$ & $\begin{array}{l}\text { Air flow sensors } \\
\text { (for DOAS) }\end{array}$ & $\begin{array}{l}\text { Air monitor fan evaluators } \\
\text { paired to DPT2500 Plus } \\
\text { transmitters }\end{array}$ & DOAS & 1 & $\begin{array}{c}\text { DTP2500: } 0.25 \% \text { of } \\
\text { natural span, including } \\
\text { hysteresis, deadband, } \\
\text { nonlinearity, and } \\
\text { nonrepeatability; } \\
\text { fan evaluator: } \pm 2 \% \\
\end{array}$ \\
\hline \multirow[t]{4}{*}{ Power } & Wattnode & $\begin{array}{l}\text { Continental Controls WNB-3D- } \\
240 \mathrm{P}, 100 \mathrm{~Hz} \text { option }\end{array}$ & ID units & 11 & $\pm 0.5 \%$ of reading \\
\hline & $\mathrm{CT}$ & $\begin{array}{l}\text { Continental Controls ACT-0750- } \\
005\end{array}$ & ID units & 22 & $\pm 0.75 \%$ of reading \\
\hline & Wattnode & $\begin{array}{l}\text { Continental Controls WNB-3D- } \\
240 \mathrm{P}, \\
100 \mathrm{~Hz} \text { option }\end{array}$ & OD unit & 1 & $\pm 0.5 \%$ of reading \\
\hline & $\mathrm{CT}$ & $\begin{array}{l}\text { Continental Controls ACT-0750- } \\
020\end{array}$ & OD unit & 3 & $\pm 0.75 \%$ of reading \\
\hline
\end{tabular}




\section{COOLING SEASON ANALYSIS}

The cooling season analysis is based on the measured data from July 11, 2015, through September 12, 2015. During this period, the RTU and VRF systems were operated under 50, 75, and $100 \%$ load conditions alternately, as described earlier. The performance of the RTU and VRF systems was compared in terms of (1) energy use, (2) the ability to maintain room temperature, and (3) system efficiency. The energy use and thermal performance comparisons were performed using measured hourly data for occupied hours only, excluding the startup hours (i.e., 8 a.m. to 6 p.m.). The COP analysis was performed using both hourly and 1-minute data.

\subsection{HOURLY THERMAL CONDITION ANALYSIS—OCCUPIED HOURS ONLY}

Figure 6 shows the measured hourly room temperature statistics (minimum, first quartile, median, third quartile, and maximum) for occupied hours excluding the startup hours (8 a.m. to 6 p.m.) in all rooms during RTU and VRF system operation at the three load conditions. Outdoor air temperature statistics are also plotted. The thermostat cooling set point is marked as a blue line across the plot. Temperature statistics in unconditioned rooms are shaded in gray.

The data analysis shows that both the RTU and the VRF systems maintained room temperature well, especially in the first-floor rooms. In general, the VRF system maintained room temperature in a slightly tighter range compared with the RTU system. Some rooms on the second floor were slightly undercooled for both systems during 100\% operation. For 100\% VRF system operation, rooms 204, 205, and 206 showed slight undercooling, which implies that the VRF indoor units might be slightly undersized. For 100\% RTU operation, only room 206 showed slight undercooling, and rooms 202, 203, and 204 were overcooled.

For partial room operation, both systems maintained room thermostat set point temperatures well for the conditioned rooms. However, the unconditioned room temperatures during the RTU part-load schedules were lower than the ones during the corresponding VRF part-load schedules. This likely was the case because the room air was better isolated during VRF system operation. During part-load operation for the RTU system, the VAV boxes in the unconditioned rooms were forced to close to prevent these rooms from being directly conditioned. However, there could have been some leakage through the damper in the VAV box that allowed a small amount of conditioned air to be provided to the unconditioned zones. In addition, the return air grilles connecting to the return air plenum of the RTU were not closed, resulting in depressurization of the unconditioned rooms while the RTU supply fan was running. This

depressurization may have caused conditioned air from other rooms to be pulled into the unconditioned rooms via door undercuts or other leakage paths. The addition of this conditioned air by either VAV damper leakage or pressure-driven air movement from conditioned rooms could have contributed to lower room temperatures in the unconditioned rooms during RTU operation. 

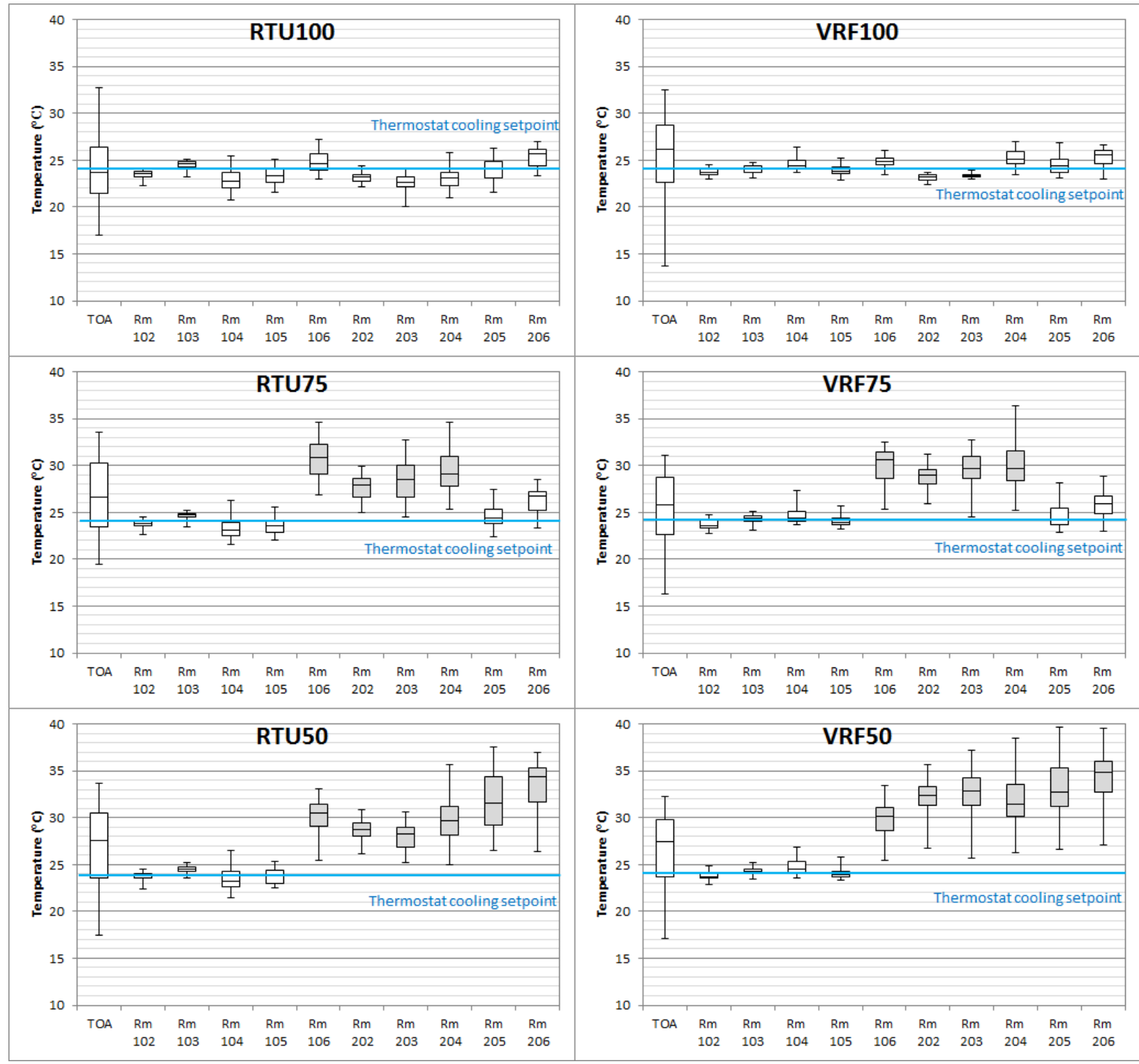

Figure 6. Room temperatures during RTU and VRF system operation at different capacities.

\subsection{PERFORMANCE DURING TYPICAL SUMMER DAYS}

Figure 7 shows the hourly energy consumption and room temperatures for typical summer days during RTU and VRF system operation at the three load schedules. Days with relatively similar outdoor air temperature profiles were selected to provide a reasonable comparison. Only the temperatures for rooms $102,103,104$, and 105 were plotted, since they were conditioned during all load schedules.

Data analysis shows that, in general, the systems showed similar energy use patterns, i.e., high energy use during startup at 6:00 a.m. to reach the thermostat set point (i.e., $24^{\circ} \mathrm{C}$ ) as the occupancy mode changed from "unoccupied" to "occupied," a drop in energy use as the room temperature reached the thermostat set point, and a gradual increase in energy use as the outdoor temperature rose during the day.

The comparison shows that the RTU used more energy (as much as 30\% more than the VRF system) during system startup, particularly for 50 and $75 \%$ operation. A detailed look also reveals that, after the 
morning startup, the RTU system slightly overcooled some rooms to as low as $21^{\circ} \mathrm{C}$; and then it allowed the temperatures to gradually increase to up to $26^{\circ} \mathrm{C}$ at 6:00 p.m. The VRF system, in general, maintained a tighter range of room temperatures across the rooms; achieved a temperature as low as $23^{\circ} \mathrm{C}$ after the morning startup, indicating a lower tendency to overcool; and maintained room temperatures within a 24 to $25^{\circ} \mathrm{C}$ range throughout the day. The exception was room 104, where the temperature was higher than in the other rooms during VRF system operation in all modes.

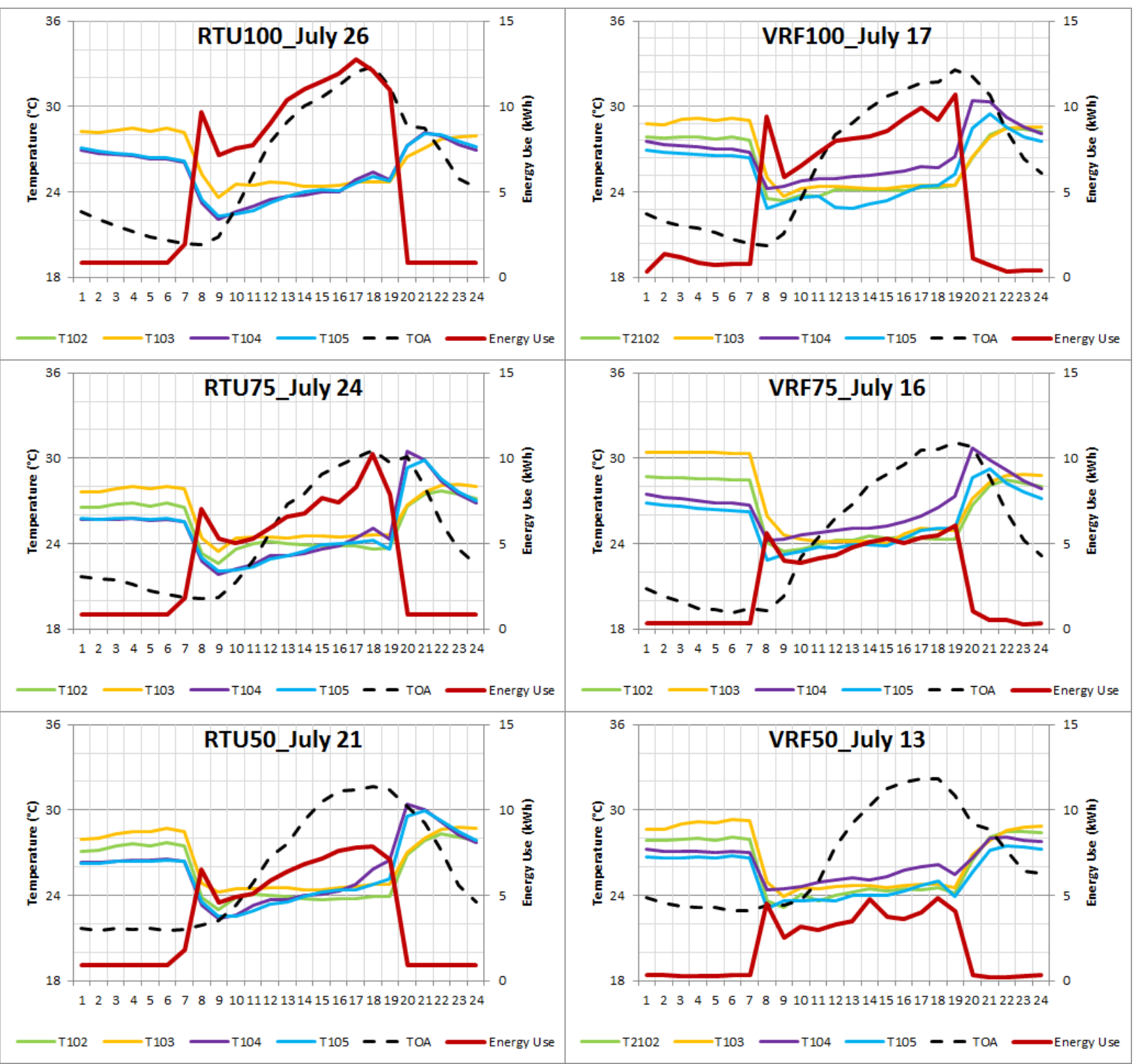

Figure 7. Room temperature and energy use for a typical day during RTU and VRF system operation at different loads. 


\subsection{POWER CONSUMPTION ANALYSIS}

Figure 8 shows a power consumption comparison during the occupied hours when the RTU and VRF systems were operated under varying loads. The VRF system responded more efficiently to the reduced loads (i.e., use less energy for lower loads), as seen from the lower scatter in the data points for the three loads. The energy use by the RTU system was more scattered during part-load conditions, resulting in more overlapping points for the 50 and $75 \%$ load schedules. These results indicate that the VRF system does a better job of isolating zone air during operation, whereas return air from conditioned zones and warm air from unconditioned zones mixes in the plenum during RTU system operation.
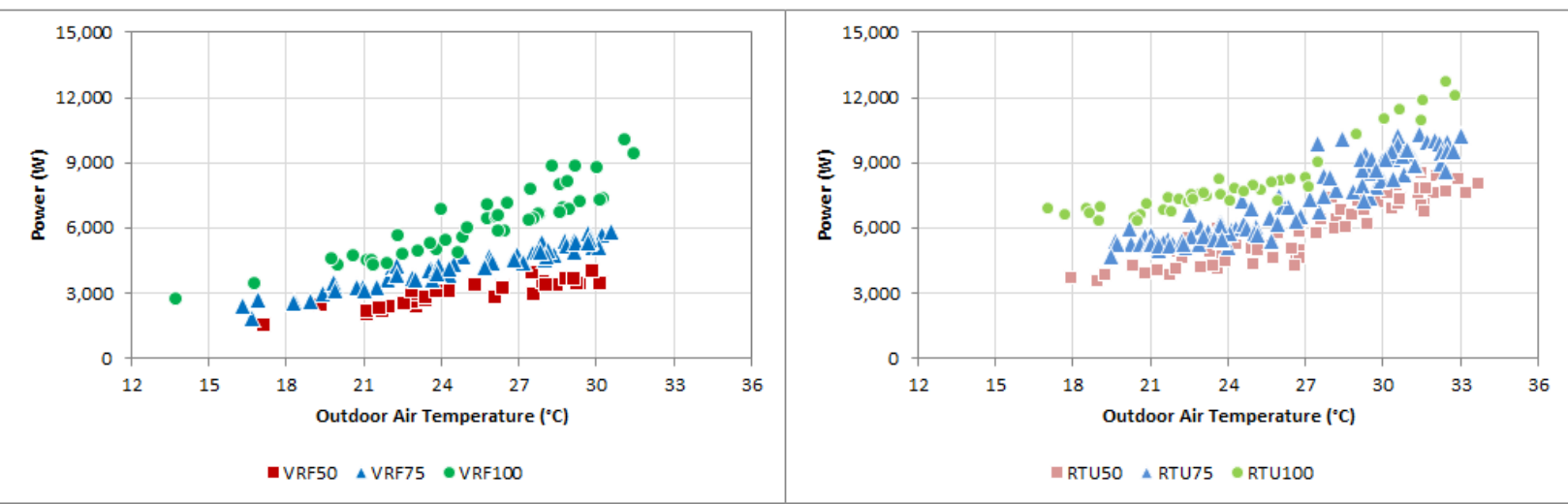

Figure 8. Comparison of hourly power consumption during occupied hours at varying loads. (Left) Data points from the VRF system operation; (right) data points from RTU system.

A comparison of these data across the VRF and RTU systems by load in Figure 9 shows that energy use was higher for the RTU system than for the VRF system at full- and part-load conditions. To predict the hourly energy use for each operation in the entire cooling season, best-fit regression models for RTU and VRF hourly energy use were also developed, as shown in Figure 9. Table 4 presents the regression models for the RTU and VRF hourly energy use based on the average hourly outdoor air temperature.

Figure 10 shows a comparison of predicted average daily cooling season energy use between the VRF and RTU systems at different loads. Only weekdays from July through September 2015 and occupied hours (including startup) are accounted for. The predicted energy use was calculated using the weather normalized curve-fit for the measured data shown in Figure 9. The VRF system saved $21 \mathrm{kWh} /$ day (30\%), $21 \mathrm{kWh} /$ day (37\%), and $21 \mathrm{kWh} /$ day (47\%) of cooling energy use at 100, 75, and 50\% loads, respectively.

Figure 10 also shows the energy savings from the VRF system at different load conditions for a range of outdoor air temperatures observed during the monitoring period. As expected, the savings for the VRF system were higher when the building was partially conditioned. At outdoor temperatures above $27^{\circ} \mathrm{C}$, the savings for the VRF system remained slightly above $20 \%$; the savings were higher at milder temperatures. Savings for the VRF system at $50 \%$ load were consistently higher than at $75 \%$ load. At these part loads, savings were slightly above 30 and $40 \%$ at outdoor air temperatures between 21 and $27^{\circ} \mathrm{C}$; they rose gradually beyond this temperature range. 


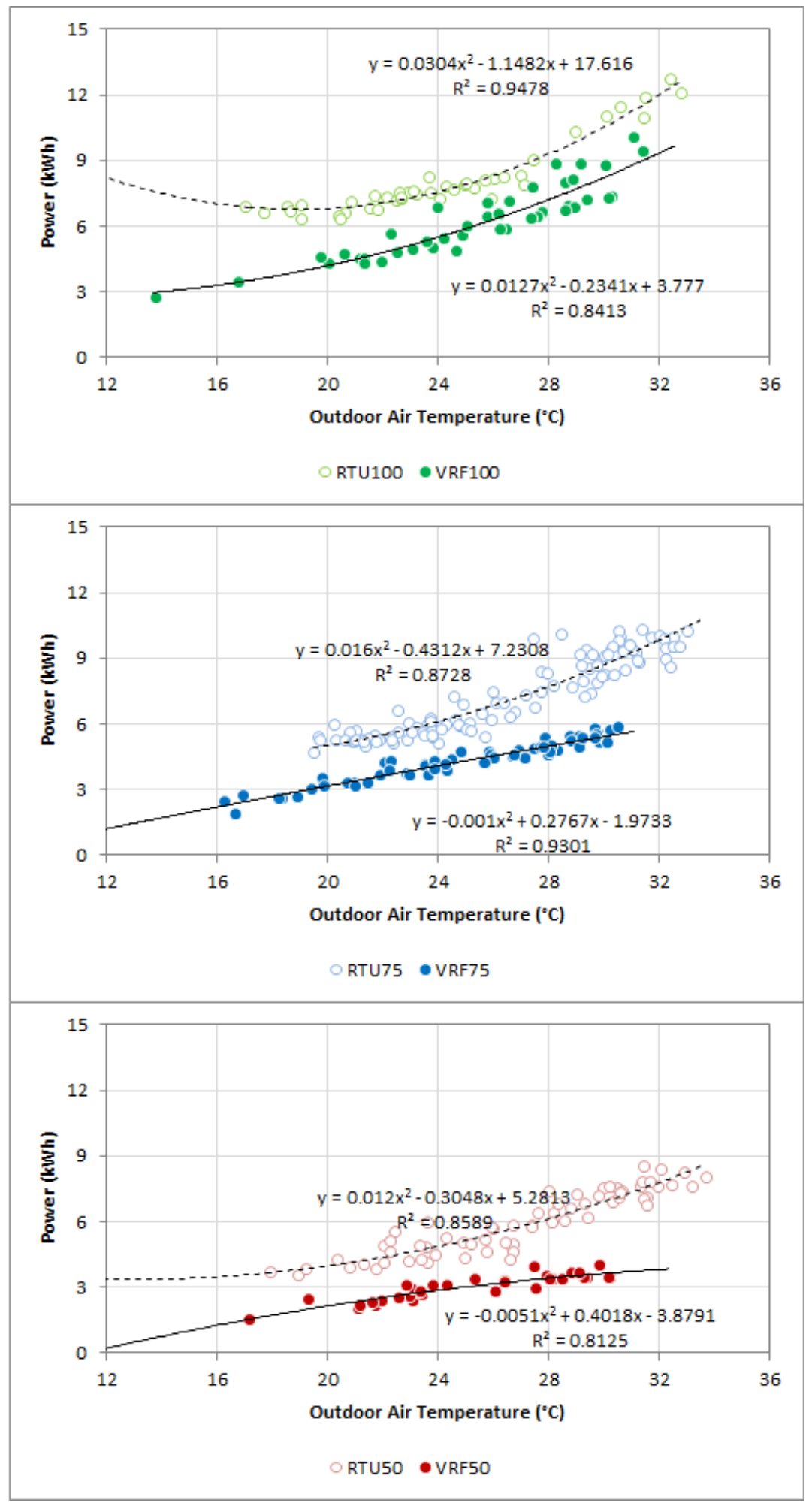

Figure 9. Comparison of power consumption by VRF and RTU systems at each load condition. 
Table 4. Regression models for power consumption for cooling season

\begin{tabular}{llcc}
\hline \multicolumn{1}{c}{ Category } & Operation & Regression models for power consumption & $\mathbf{R}^{\mathbf{2}}$ \\
\hline RTU hourly & RTU100 & $0.0304 x^{2}-1.1482 x+17.616$ & 0.95 \\
energy use & RTU75 & $0.016 x^{2}-0.4312 x+7.2308$ & 0.87 \\
(kWh) & RTU50 & $0.012 x^{2}-0.3048 x+5.2813$ & 0.86 \\
\hline VRF hourly & VRF100 & $0.0127 x^{2}-0.2341 x+3.777$ & 0.84 \\
energy use & VRF75 & $-0.001 x^{2}+0.2767 x-1.9733$ & 0.93 \\
(kWh) & VRF50 & $-0.0051 x^{2}+0.4018 x-3.8791$ & 0.81 \\
\hline
\end{tabular}

Where $x$ : hourly outdoor air temperature $\left({ }^{\circ} \mathrm{C}\right)$

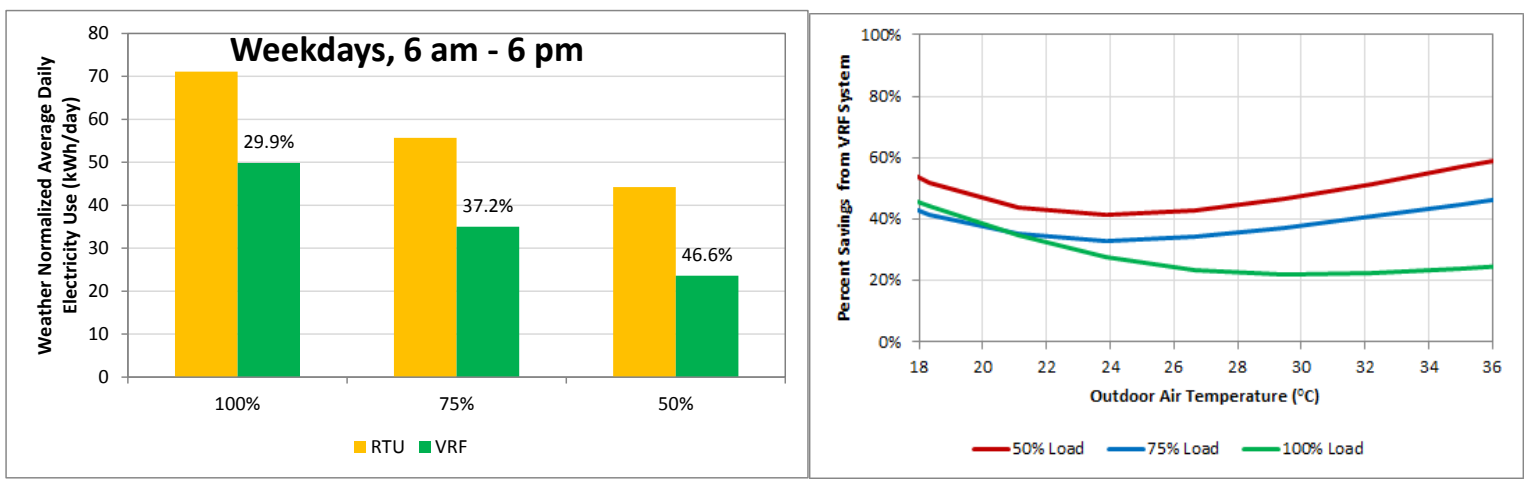

Figure 10. Energy savings from VRF system at different loads.

\subsection{COP ANALYSIS}

Figure 11 shows the COP of the VRF and RTU systems with respect to outdoor air temperature. As discussed earlier, the operating efficiency of the VRF system was more sensitive to outdoor temperaturedriven loads (i.e., COP is lower at cooler temperatures). At lower outdoor air temperatures, the impact of zone control-driven variability in loads was observed. At higher temperatures, that impact diminished. The efficiency of the RTU system showed a similar trend (lower COP at 50\% load, even lower at cooler temperatures), but the impact was less pronounced. Over the data monitoring period, the average cooling COP was 4.2, 3.9, and 3.7 for the VRF system and 3.1, 3.0, and 2.5 for the RTU system under 100, 75, and 50\% load conditions, respectively. Those results show 35, 30, and 48\% improvement in COP for 100, 75 , and $50 \%$ load conditions, respectively. 

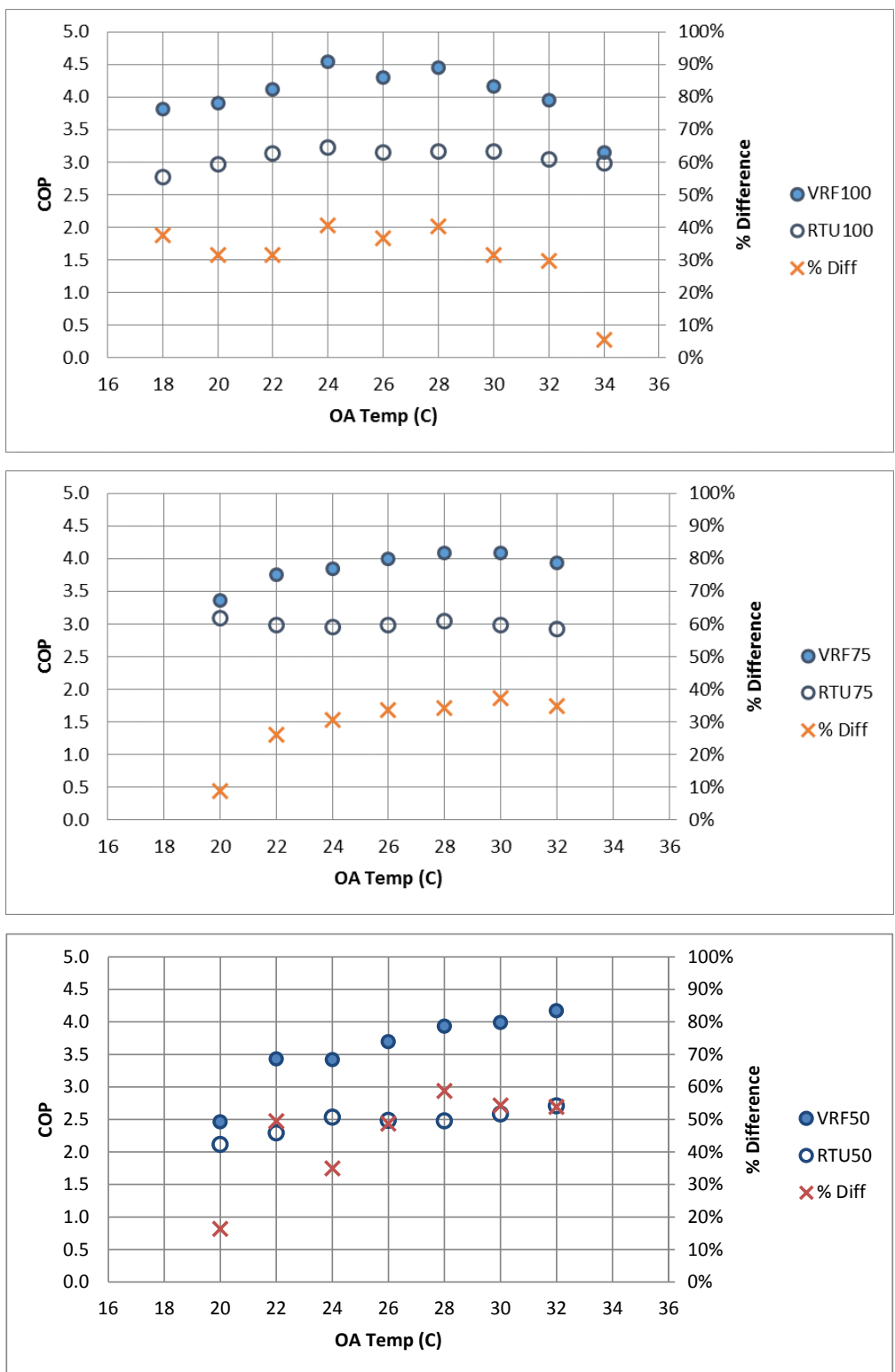

Figure 11. COP comparison between RTU and VRF systems (top: 100\% operation; center: $75 \%$ operation; bottom: 50\% operation).

\subsection{QUASI-STEADY-STATE COP ANALYSIS}

Analyzing high-resolution data (i.e., 1 minute data) allows further insight into the equipment operation by enabling the filtering of near steady-state data and the separation of the data by operating stage or capacity. The following sections will analyze the equipment performance from a quasi-steady-state perspective and then determine the impact of cycling losses on each system.

\subsubsection{RTU Quasi-Steady-State Data Analysis}

Analyzing the data at a higher resolution allows for quasi-steady-state data to be extracted and provides further insight into the performance of the systems. The analysis requires a set of criteria for establishing when quasi-steady-state conditions are achieved. Two periods of operation were removed from the data to avoid transient effects: (1) initial startup of the unit and (2) the last minute of data in a cycle when the 
compressor has shut off but there is still airflow. To determine how many minutes of data at the start of each cycle should be eliminated from the quasi-steady-state data set, the efficiency of the system was plotted against the time into the cycle. For the RTU, these data are shown for low-stage operation in Figure 12. Based on these data, a minimum time into a cycle of 6 minutes was selected for all quasisteady-state data. In addition, a minimum of 4 minutes of runtime after a change from high to low or low to high stage was imposed on the RTU quasi-steady-state data.

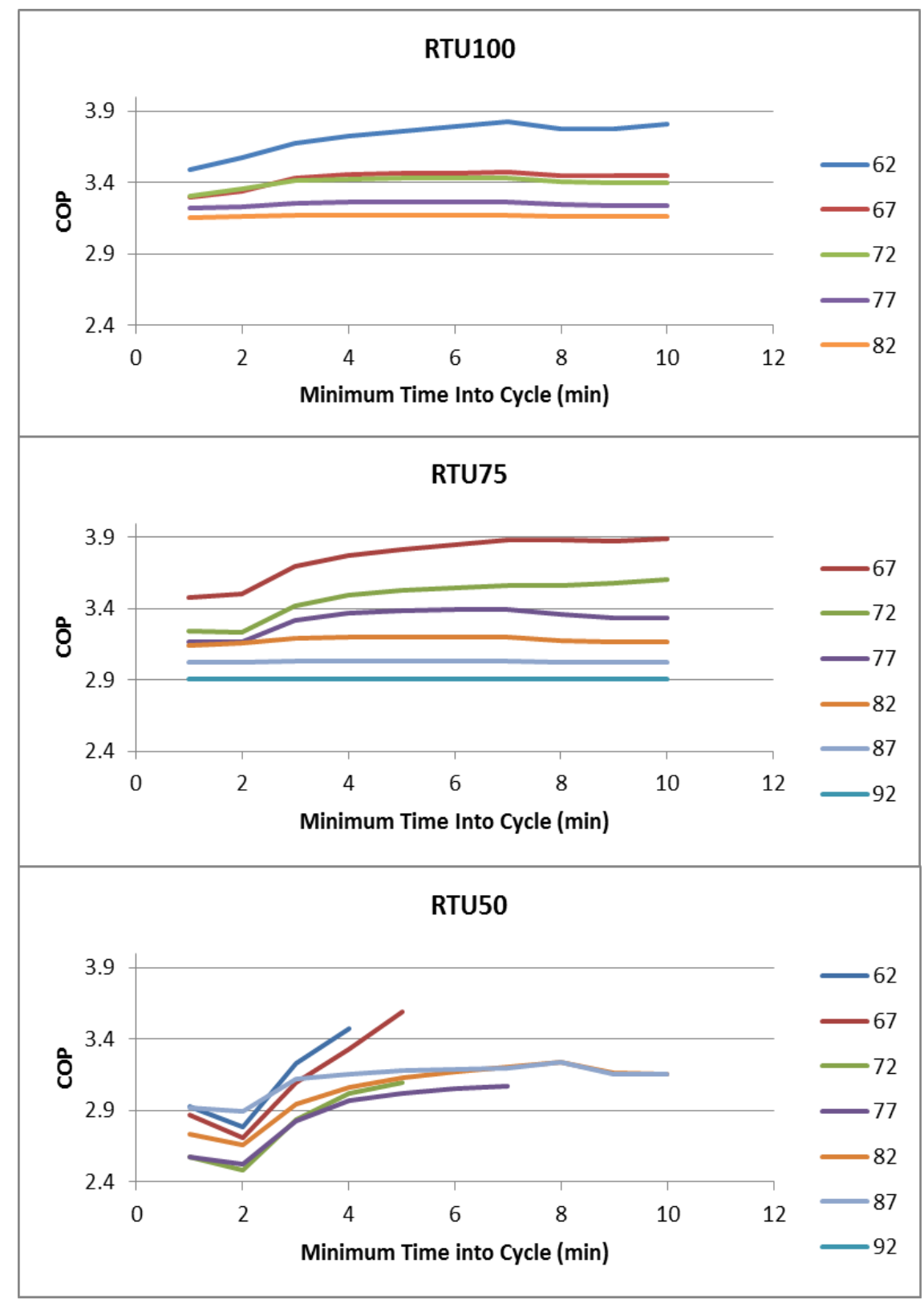

Figure 12. Determination of quasi-steady-state minimum time into cycle for RTU.

Using the quasi-steady-state data set, the COP of the RTU was plotted against outdoor temperature in Figure 13. The outdoor air temperature was binned in $2.8^{\circ} \mathrm{C}$ increments; e.g., the $25^{\circ} \mathrm{C}$ bin includes temperatures greater than or equal to $23.9^{\circ} \mathrm{C}$ and less than $26.7^{\circ} \mathrm{C}$. The data were also divided by compressor staging, with the low stage representing single-compressor operation and the high stage representing dual-compressor operation. As expected, the efficiency of the system decreased with 
increasing ambient temperature. The RTU was also generally more efficient running with all of the VAV boxes open, RTU100, compared with the cases with some of the of the VAV boxes closed. There was not a consistent trend between the efficiency of the high and low stages for the three different configurations The RTU100 data showed higher efficiency in the high stage, the RTU75 data showed similar performance in both stages, and the RTU50 data showed higher efficiency in the low stage.

Looking at indoor airflow in Figure 14 shows that closing some of the VAV boxes reduced the airflow through the unit. Since the RTU supply air fan was set up to maintain a constant static pressure in the duct system, when VAV boxes are closed and the overall resistance in the duct system increases, the supply airflow must be reduced to maintain the static pressure. Note also that the airflow was essentially the same for both high- and low-stage operation.

The constant airflow for different stages and the variation of airflow under various VAV box configurations resulted in a wide variation in the ratio of airflow to total cooling capacity, $300-900 \mathrm{~m}^{3} / \mathrm{h}$ per ton, and in the sensible heat ratio (ratio of sensible cooling to total cooling) of the system, $\sim 0.5-0.9$ (Figure 15 and Figure 16, respectively). The RTU achieved the highest efficiency when an optimal balance was achieved between cooling capacity, airflow, and fan power. However, the system is controlled in such a way that this optimal combination is not frequently achieved.

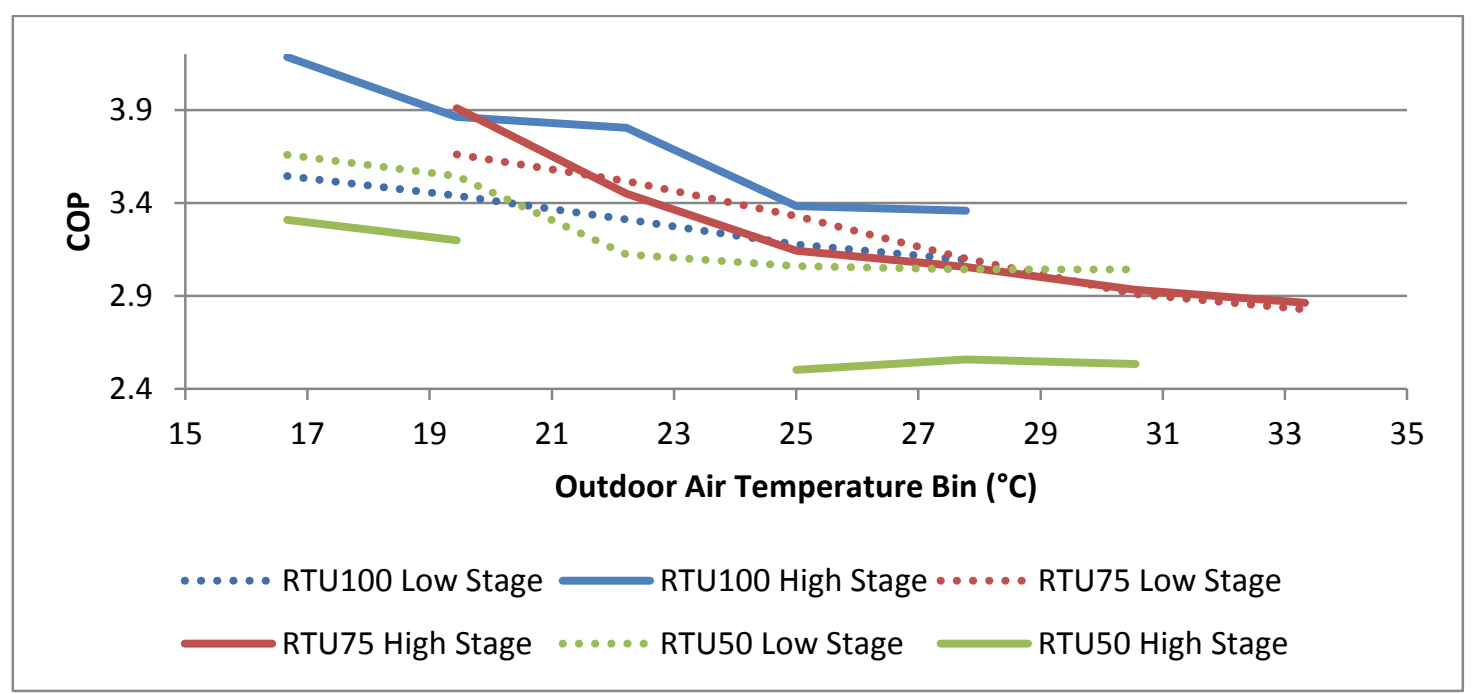

Figure 13. Comparison of RTU efficiency during different schedules and under different outdoor air temperatures. 


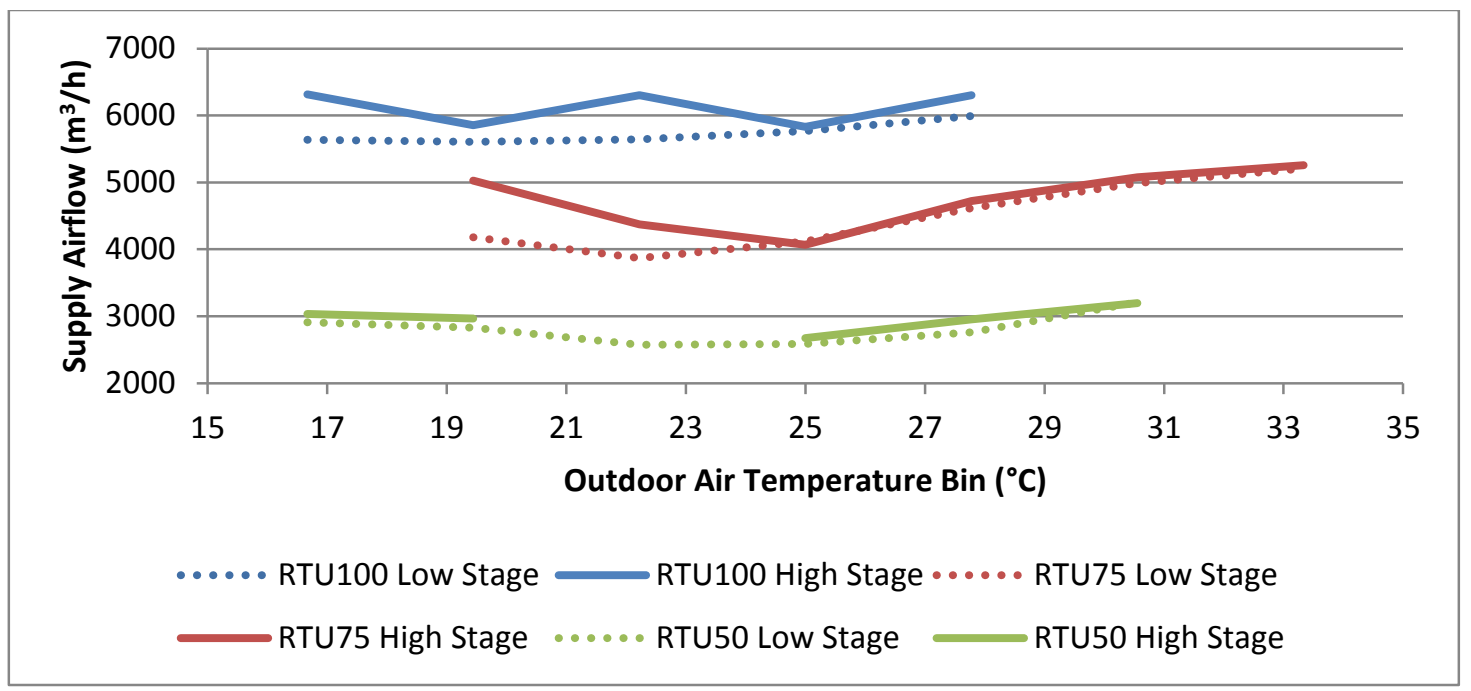

Figure 14. Comparison of RTU indoor airflow during different schedules.

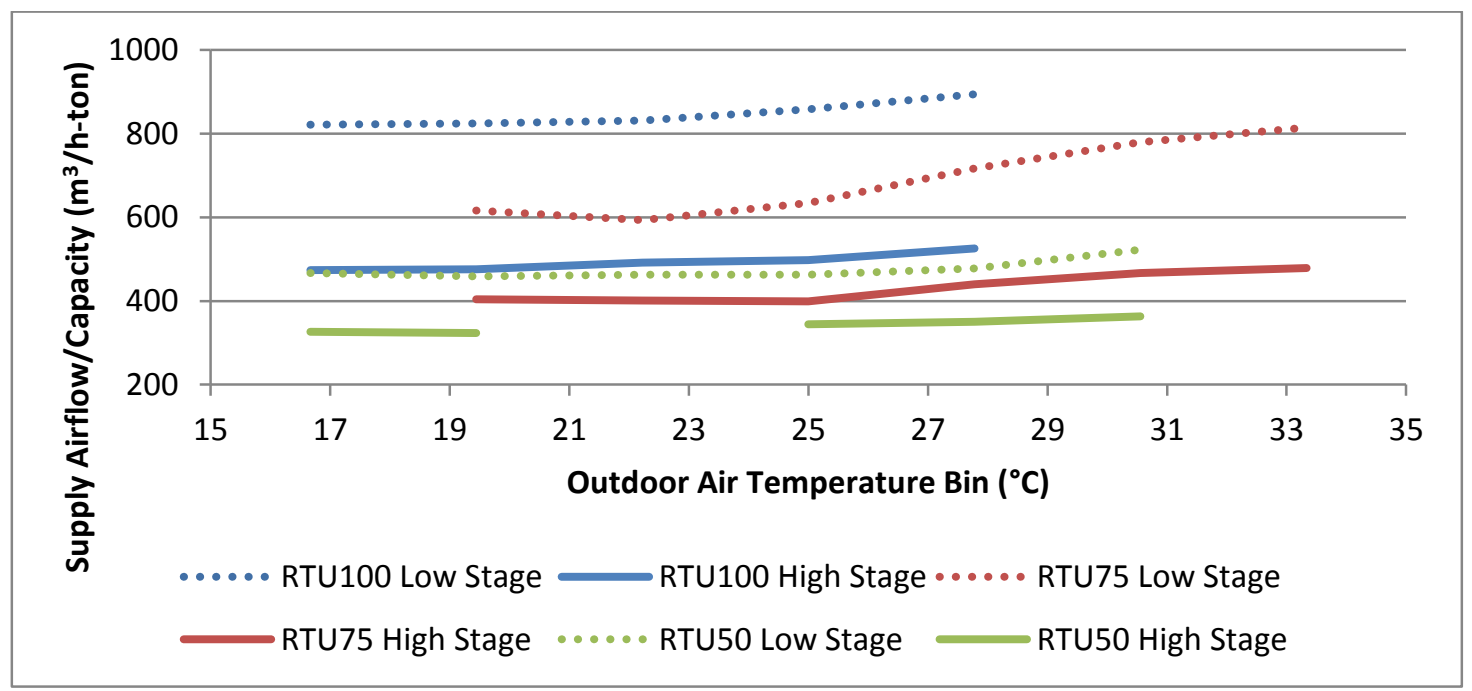

Figure 15. Comparison of RTU ratio of supply airflow to total cooling during different schedules. 


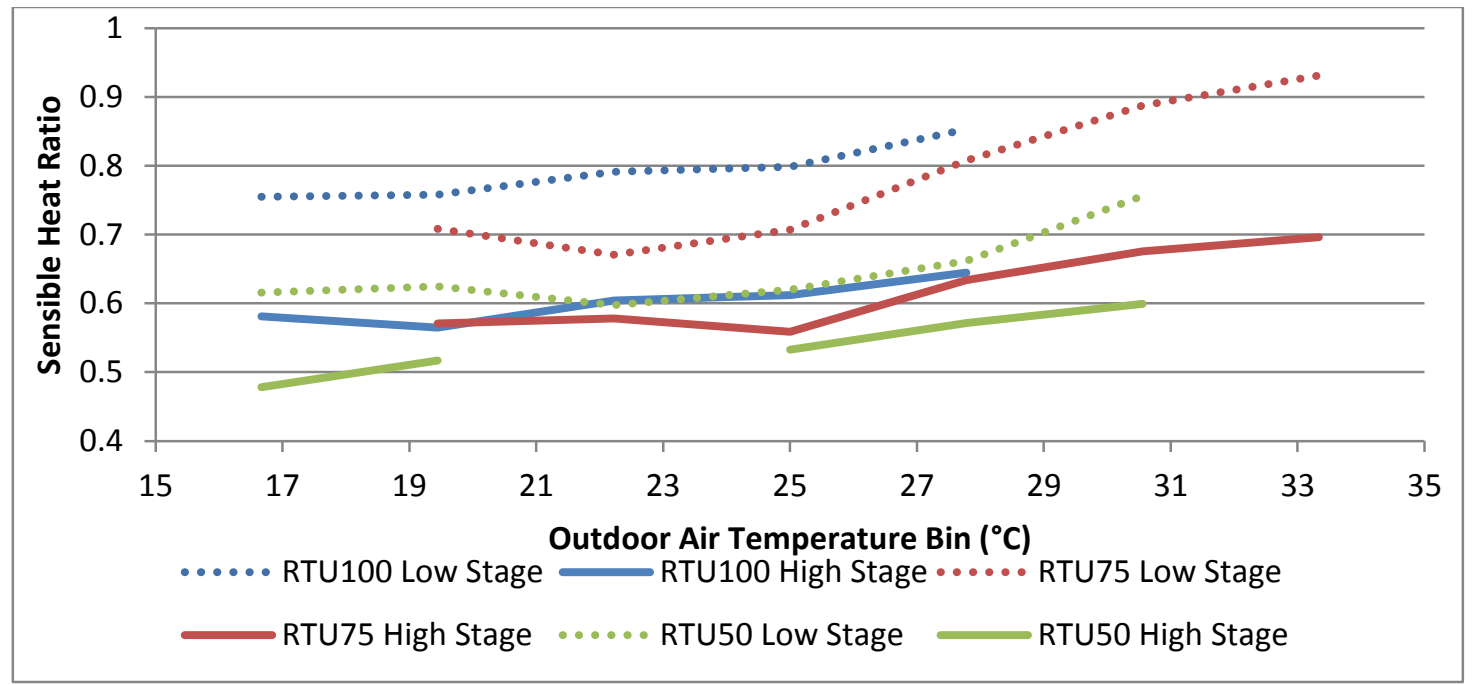

Figure 16. Comparison of RTU sensible heat ratio during different schedules.

\subsubsection{RTU—Impact of Cycling Losses}

The discussion above examined quasi-steady-state data only where the losses associated with cycling were minimized. However, in the real world, cyclic losses can play a major role in equipment efficiency. Figure 17 shows the average compressor runtime per cycle for the RTU. The low-stage compressor runtime was calculated as the runtime in both the low and the high stages, since the low-stage compressor is active in both modes whereas the high-stage compressor is active only in high-stage mode. The average runtime per cycle for the high stage was very low for all schedules: $\sim 4$ minutes per cycle.

However, the low-stage compressor runtime per cycle increased with outdoor air temperature and when conditioning a greater volume of space, as expected. The ratio of the measured COP using all data, to the COP using only the quasi-steady-state data set, can be used to illustrate the losses associated with cycling, as seen in Figure 18. The low stage shows little if any cycling loss during the RTU100 schedule, which had average runtimes per cycle of over 13 minutes for all outdoor temperatures. The RTU75 schedule had low-stage losses that were slightly more significant - up to 8\% - at lower outdoor temperatures, when the average runtime per cycle was 11 minutes or less. The low-stage RTU50 cycling losses were up to $20 \%$ at mild outdoor temperatures and decreased to $\sim 5 \%$ at the $92^{\circ} \mathrm{F}$ outdoor air temperature bin. As the cooling load on the system was decreased by closing off VAV boxes, the RTU became effectively more and more oversized for the load. This resulted in additional cycling and loss of efficiency. Since the unit refrigerant circuits for the two compressors were interlaced on both the condenser and evaporator, there was comparably less cyclic loss for second-stage operation despite a very low average runtime per cycle, less than 5 minutes. This was because the first-stage cooling operation pre-cooled the second-stage cooling circuits via conduction and convection, reducing losses associated with cooling the thermal mass of the coil. 


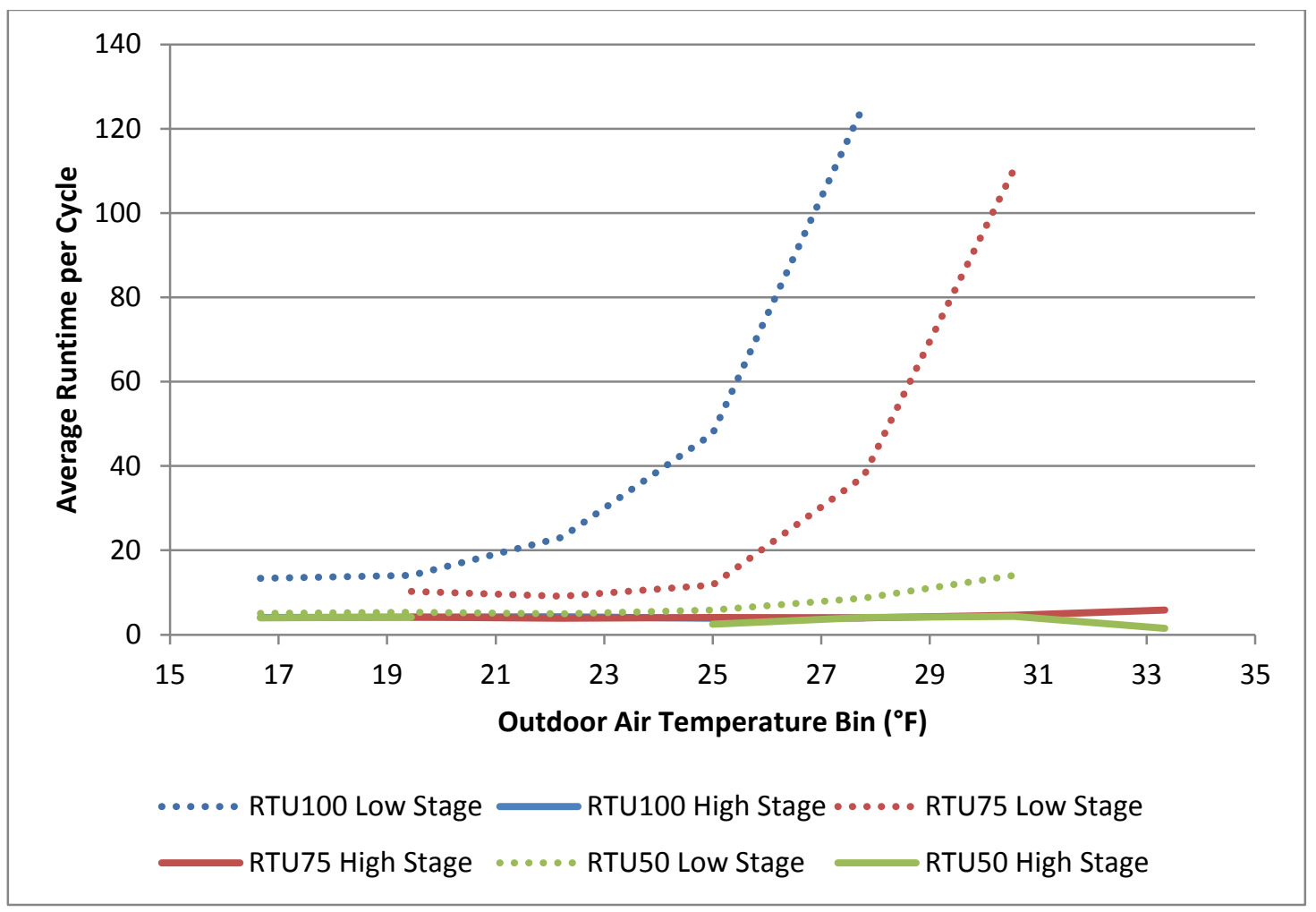

Figure 17. Comparison of RTU average compressor runtime per cycle for different operation schedules.

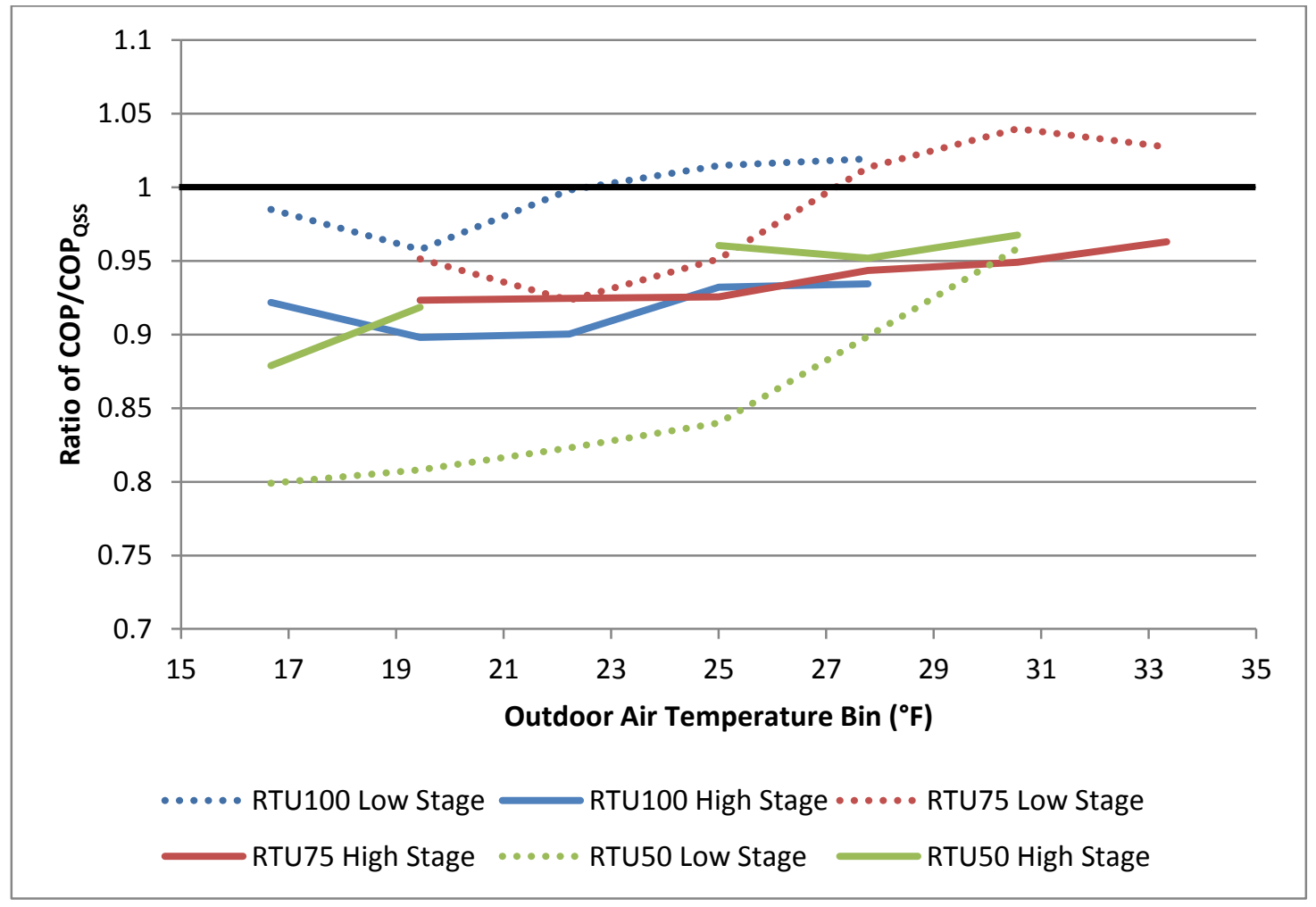

Figure 18. Comparison of cycling losses for the RTU during different operation schedules. 


\subsubsection{VRF Quasi-Steady-State Analysis}

The VRF data were filtered in the same fashion as the RTU data, using a 10-minute minimum runtime as the limit for quasi-steady-state data. This schedule included a 10-minute minimum runtime between the time when individual indoor units turn on or off. An indoor unit was considered to be actively cooling if the fan was operating and the temperature differential between the return and supply was greater than $10^{\circ} \mathrm{F}$. The efficiency of the system during the three different schedules is shown in Figure 19. The VRF100 schedule shows the highest efficiency over most of the temperature range, with the other schedules having similar efficiency at high outdoor air temperatures.

Figure 19 tells only part of the story, though, because the VRF system capacity can be varied by turning indoor units on and off, as was done with the various schedules, and by varying the compressor speed to adjust the cooling capacity delivered to the active units. Figure 20 shows a plot of the system COP as a function of outdoor air temperature and of the ratio of the rated capacity of the actively cooling indoor units to the total rated indoor unit capacity. The data from the different schedules are shown with different styles of markers, and the color of the marker and the label indicate the average COP for the data. Generally, the more indoor units that are actively cooling, the higher the system efficiency.

To examine the impact of compressor speed on efficiency, the data were filtered to include only times when the rated cooling capacity of the active indoor units was $80 \%$ of the total rated indoor capacity. This filtering limited the data to times when nearly all of the indoor units were providing cooling. The actual cooling capacity was then divided by the total rated cooling capacity, and these data was placed into 0.1 increment bins. The efficiency of this binned data was plotted against the binned outdoor air temperature data, as seen in Figure 21. These data show that, in general, the VRF system was more efficient when operating at lower compressor speeds, indicated by lower capacity in this case.

The quasi-steady-state data analysis indicates that the VRF system operated most efficiently when all indoor units were actively cooling and the compressor was operating at reduced speed. When indoor units were shut off, the cumulative size of the indoor heat exchanger was effectively reduced, thereby reducing the efficiency. However, as shown in the hourly analysis, this efficiency penalty was less than the energy saved by the reduced cooling load due to unoccupied zones not being conditioned. 

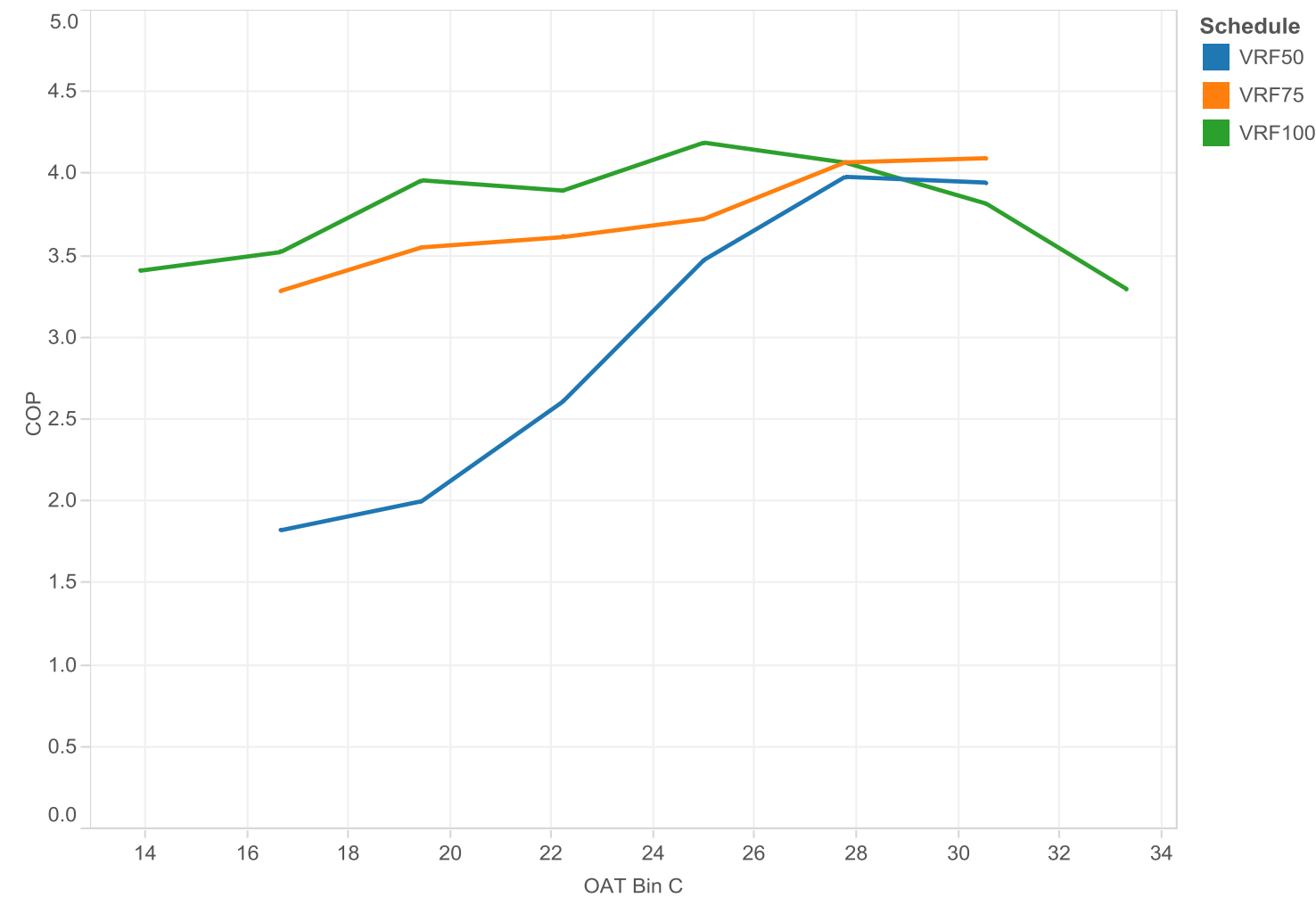

Figure 19. Comparison of VRF efficiency during different operating schedules.

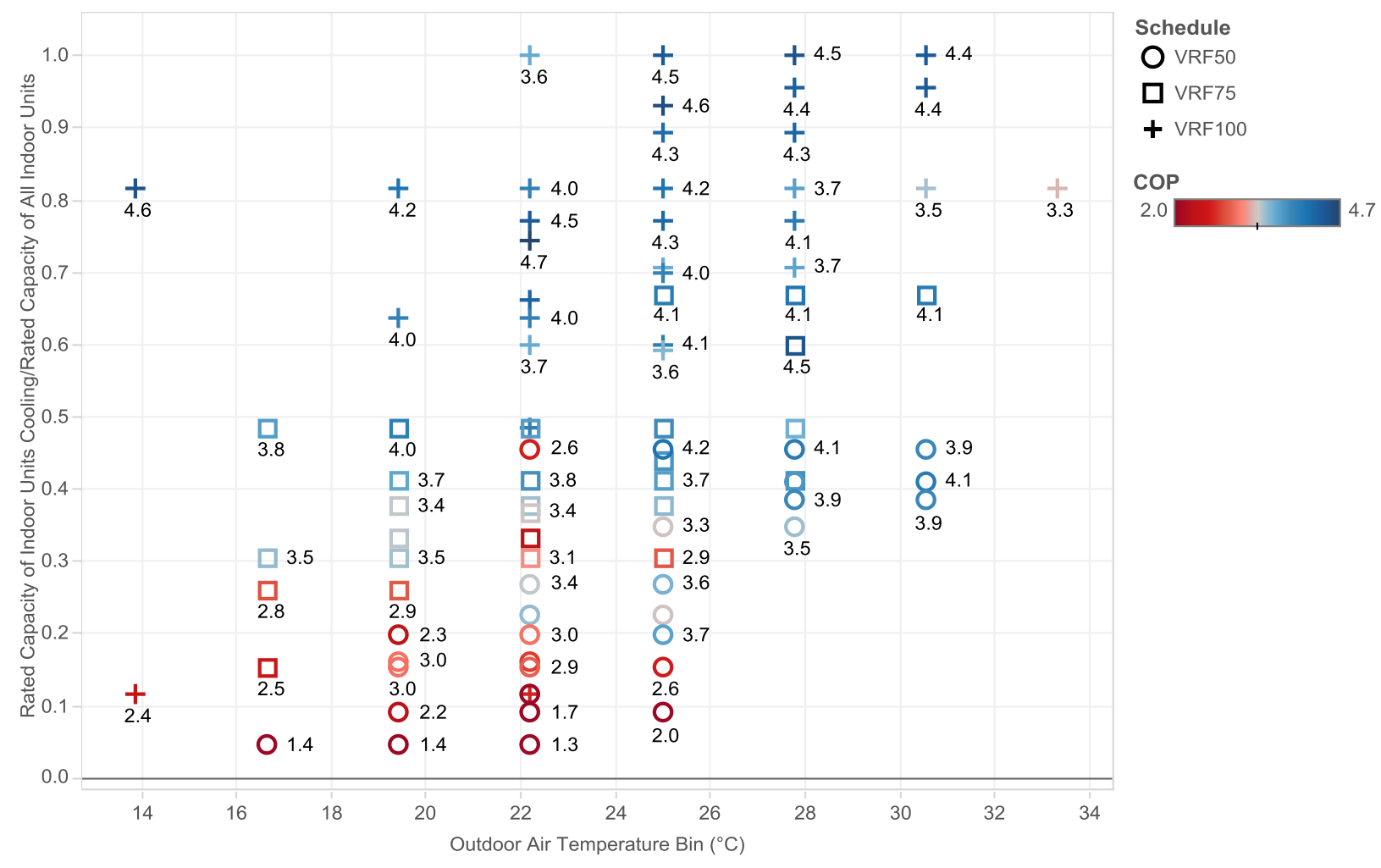

Figure 20. Impact of the rated capacity of active indoor units on the efficiency of the VRF system. 


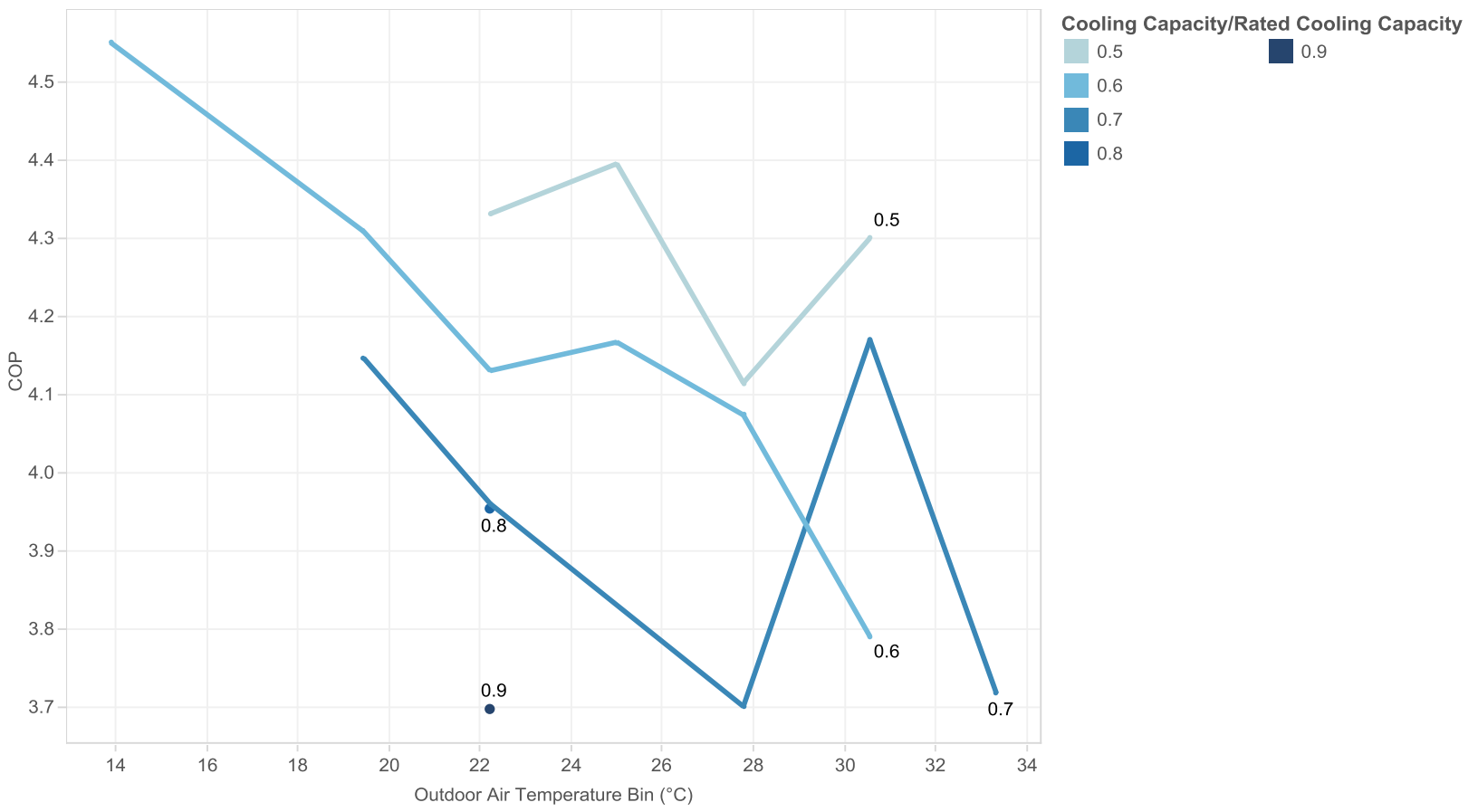

Figure 21. Efficiency of VRF system when the rated cooling capacity of the active indoor units divided by the total rated cooling capacity was at least 0.80 .

\subsubsection{VRF - Impact of Cycling Losses}

Analyzing the cycling losses of the VRF system was difficult because the temperature difference between the return and supply of an indoor unit was used to determine whether it was cooling or not. This inherently eliminated some of the startup and shutdown operation. However, the indoor coils are located in the conditioned space, unlike the RTU coils, so these losses should be minimal. The VRF unit also uses a variable-speed compressor, resulting in longer compressor runtimes with less cycling. A comparison of the COP for all of the data to that for the quasi-steady-state data is shown in Figure 22. The VRF100 and VRF75 schedules show at most a 10\% loss in efficiency during low-ambient cooling. The VRF50 data actually showed some improvements in efficiency when all of the data were included. This could be due to the indoor units' cycling on and off more frequently, resulting in more time during which the units were cooling, but the temperature differential between the return and the supply was less than the $10^{\circ} \mathrm{F}$ limit that was imposed to indicate the unit was cooling. 


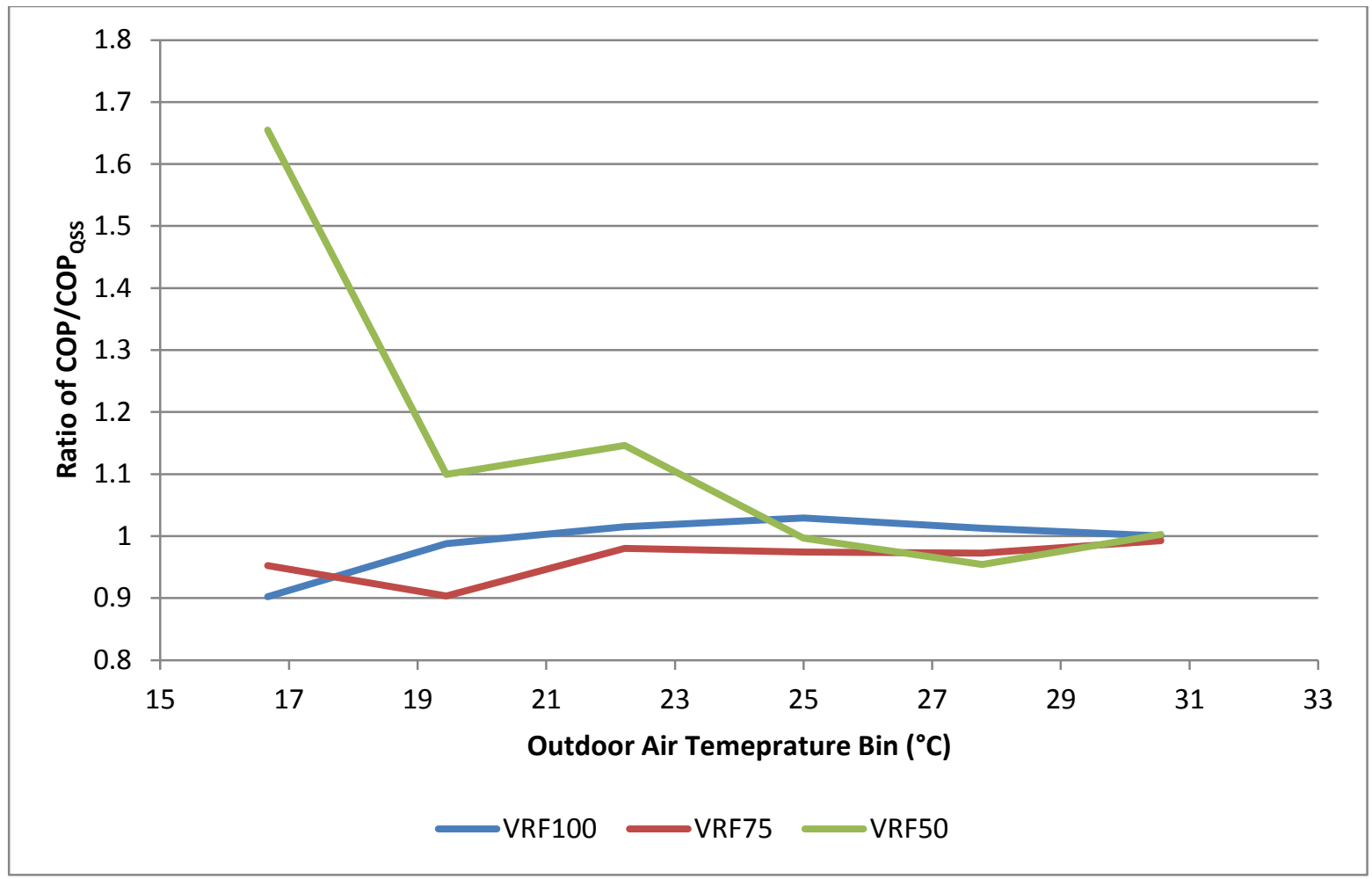

Figure 22. Comparison of efficiency for VRF system operating during different schedules for all data and quasi-steady-state data only. 


\section{CONCLUSION}

\subsection{SUMMARY AND CONCLUSION}

This study compares the full- and part-load performance of the VRF system with the baseline RTU/VAV system in a two-story, $300 \mathrm{~m}^{2}$ multi-zone building with emulated office occupancy. To carry out the comparison, full- and part-load conditions (i.e., 100, 75, and 50\% loads) in the building were maintained alternately by conditioning either the entire building or selected zones, and emulating the occupancy, accordingly. During the study period, each system was operated alternately under each of the three load conditions for 2-3 days; and the system parameters, indoor and outdoor conditions, loads, and energy use were monitored. The cooling season performance and energy use of both systems was monitored in the summer of 2015. The system performance was evaluated in terms of weather-normalized HVAC energy consumption, the ability to maintain the desired indoor temperature in the conditioned zones, and the seasonal average COP. Furthermore, the energy savings potential of using VRF systems in major US cities was evaluated using hourly building energy simulations calibrated with the measured data from the measured data in the building. The following are the key findings and lessons learned from this case study.

\section{Cooling Season Analysis}

- Hourly zone temperature analysis shows that both RTU and VRF systems maintained room temperature very well, especially in the first-floor rooms. The second-floor rooms were generally slightly overheated. The VRF system maintained room temperature in a slightly tighter range compared with the RTU system.

- The energy savings for the VRF system compared with the RTU system for the cooling season are estimated to be 30,37 , and $47 \%$ under the 100,75 , and $50 \%$ load conditions, respectively.

- The COP analysis based on 1 hour data shows that the average cooling COP was 4.2, 3.9, and 3.7 for the VRF system and 3.1, 3.0, 2.5 for the RTU system under the 100, 75, and 50\% load conditions.

- The quasi-steady-state data analysis indicates that the VRF system operates most efficiently when all indoor units are actively cooling and the compressor is operating at a reduced speed. 



\section{REFERENCES}

ASHRAE. 2013. ANSI/ASHRAE Standard 62.1-2013. Ventilation for Acceptable Indoor Air Quality, American Society of Heating, Refrigeration and Air-Conditioning Engineers, Atlanta.

Im, P., J. Munk, A. Gehl 2015. Evaluation of Variable Refrigerant Flow Systems Performance and the Enhanced Control Algorithm on Oak Ridge National Laboratory's Flexible Research Platform, ORNL/TM-2015/225 



\section{APPENDIX A: VRF System Specification}

\begin{tabular}{|c|c|c|c|c|}
\hline \multicolumn{2}{|c|}{ Location } & Model name & $\begin{array}{c}\text { Cooling } \\
\text { capacity } \\
(\mathrm{Btu} / \mathrm{h})\end{array}$ & $\begin{array}{l}\text { Heating } \\
\text { capacity } \\
(\mathrm{Btu} / \mathrm{h})\end{array}$ \\
\hline \multicolumn{2}{|c|}{ Ground (outside) } & AM144FXVAFH/AA & 144,000 & 162,000 \\
\hline \multicolumn{2}{|l|}{ DOAS } & AM140HNEPCH/MG & 47,800 & 30,400 \\
\hline \multirow{5}{*}{$\begin{array}{l}\text { Second } \\
\text { floor }\end{array}$} & Rm 202 & AM012FNNDVCH/AA & 12,000 & 13,500 \\
\hline & $\operatorname{Rm} 203$ & AM009FNIDCH/AA & 7,500 & 8,500 \\
\hline & Rm 204 & AM018FN4DCH/AA & 18,000 & 20,000 \\
\hline & $\operatorname{Rm} 205$ & AM018FN4DCH/AA & 18,000 & 20,000 \\
\hline & $\operatorname{Rm} 206$ & AM018FN4DCH/AA & 18,000 & 20,000 \\
\hline \multirow{5}{*}{$\begin{array}{l}\text { First } \\
\text { floor }\end{array}$} & Rm 102 & AM009FNIDCH/AA & 7,500 & 8,500 \\
\hline & Rm 103 & AM009FNIDCH/AA & 7,500 & 8,500 \\
\hline & Rm 104 & AM012FNNDVCH/AA & 12,000 & 13,500 \\
\hline & Rm 105 & AM018FN4DCH/AA & 18,000 & 20,000 \\
\hline & Rm 106 & AM018FN4DCH/AA & 18,000 & 20,000 \\
\hline
\end{tabular}


